\title{
Propofol Is an Allosteric Agonist with Multiple Binding Sites on Concatemeric Ternary $\mathrm{GABA}_{\mathrm{A}}$ Receptors
}

\author{
Daniel J. Shin, ${ }^{1}$ Allison L. Germann, ${ }^{1}$ Alexander D. Johnson, Stuart A. Forman, \\ Joe Henry Steinbach, and Gustav Akk
}

Department of Anesthesiology (D.J.S., A.L.G., A.D.J., J.H.S., G.A.) and the Taylor Family Institute for Innovative Psychiatric Research (J.H.S., G.A.), Washington University School of Medicine, St. Louis, Missouri; and Department of Anesthesia, Critical Care and Pain Medicine, Massachusetts General Hospital, Boston, Massachusetts (S.A.F.)

Received August 25, 2017; accepted November 27, 2017

\section{ABSTRACT}

$\mathrm{GABA}_{\mathrm{A}}$ receptors can be directly activated and potentiated by the intravenous anesthetic propofol. Previous photolabeling, modeling, and functional data have identified two binding domains through which propofol acts on the $\mathrm{GABA}_{\mathrm{A}}$ receptor. These domains are defined by the $\beta(\mathrm{M} 286)$ residue at the $\beta$ " $+"-\alpha "-$ " interface in the transmembrane region and the $\beta(Y 143)$ residue near the $\beta$ "-" surface in the junction between the extracellular and transmembrane domains. In the ternary receptor, there are predicted to be two copies of each class of sites, for a total of four sites per receptor. We used $\beta 2 \alpha 1 \gamma 2 \mathrm{~L}$ and $\beta 2 \alpha 1$ concatemeric constructs to determine the functional effects of the $\beta(\mathrm{Y} 143 \mathrm{~W})$ and $\beta(\mathrm{M} 286 \mathrm{~W})$ mutations to gain insight into the number of functional binding sites for propofol and the energetic contributions stemming from propofol binding to the individual sites. A mutation of each of the four sites affected the response to propofol, indicating that each of the four sites is functional in the wild-type receptor. The mutations mainly impaired stabilization of the open state by propofol, i.e., reduced gating efficacy. The effects were similar for mutations at either site and were largely additive and independent of the presence of other Y143W or M286W mutations in the receptor. The two classes of sites appeared to differ in affinity for propofol, with the site affected by M286W having about a 2-fold higher affinity. Our analysis indicates there may be one or two additional functionally equivalent binding sites for propofol, other than those modified by substitutions at $\beta(Y 143)$ and $\beta(\mathrm{M} 286)$.

\section{Introduction}

Propofol (2,6-diisopropylphenol) is a widely used intravenous anesthetic that acts by enhancing GABAergic inhibitory activity in the brain. Propofol can directly activate the GABA $_{A}$ receptor or, when coapplied with GABA or other agonists, potentiate the response to the transmitter (Hales and Lambert, 1991). Photolabeling and mutagenesis data have indicated that the sites mediating the actions of propofol are distinct from the orthosteric, transmitter-binding sites.

At present, two sites for propofol binding to $\mathrm{GABA}_{\mathrm{A}}$ receptors are well characterized by both photolabeling and analysis of the effects of mutations on receptor pharmacology. The first is a site located at the $\beta$ " $+"-\alpha "-$ " interface in the transmembrane region, partially defined by the $\beta 2(\mathrm{M} 286)$ and $\alpha 1$ (M236) residues (Jayakar et al., 2014). These residues are labeled by meta-azi-propofol, a photolabeling analog of propofol (Jayakar et al., 2014). Amino acid substitutions at $\beta 2$ (M286) can eliminate receptor potentiation by propofol (Krasowski et al., 1998, 2001). A tryptophan substitution at

This work was supported by the National Institutes of Health National Institute of General Medical Sciences [Grants R01GM089745 and R01GM108580] and funds from the Taylor Family Institute for Innovative Psychiatric Research.

${ }^{1}$ D.J.S. and A.L.G. contributed equally to this study.

https://doi.org/10.1124/mol.117.110403. this location $[\beta 2(\mathrm{M} 286 \mathrm{~W})]$ additionally obliterates $\mathrm{GABA}_{\mathrm{A}}$ receptor activation by the anesthetic etomidate (Stewart et al., 2008). The second characterized propofol site is defined by a pocket near the junction between the extracellular and transmembrane domains in close proximity to the "-" side of the $\beta$ subunit where ortho-propofol diazirine photolabels the $\beta(\mathrm{H} 267)$ residue (Yip et al., 2013; Franks, 2015). In $\beta 3$ homomeric and $\alpha 1 \beta 3$ heteromeric receptors, mutations to several residues lining this pocket [including $\beta$ (Y143)] modify receptor activation by propofol (Eaton et al., 2015, 2016).

There are two interfaces that contain the $\beta$ " + " $(\beta-\alpha)$ and $\beta$ “-" $(\alpha-\beta$ and $\gamma-\beta)$ surfaces in the ternary $\alpha \beta \gamma$ receptor. Thus, the photolabeling data imply the presence of four propofol-binding sites. This is supported by recent data from substituted cysteine modification and protection experiments (Nourmahnad et al., 2016). On the other hand, previous functional data are equivocal about the number of functional sites for propofol. Ruesch et al. (2012) found that there was little difference in the goodness of fit of propofol concentration-response data from the wild-type $\alpha 1 \beta 2 \gamma 2 \mathrm{GABA}_{\mathrm{A}}$ receptor when the number of sites was constrained to values between 2 and 5 .

Here, we determined the effects of mutations to the putative binding sites on $\mathrm{GABA}_{\mathrm{A}}$ receptor activation by propofol. We used concatemeric receptors containing $\beta 2 \alpha 1 \gamma 2 \mathrm{~L}$ and $\beta 2 \alpha 1$ constructs that enabled modification of each interface in a controlled and defined way. We modified the sites by 
introducing the $\beta 2(\mathrm{M} 286 \mathrm{~W})$ and the $\beta 2(\mathrm{Y} 143 \mathrm{~W})$ mutations. A total of 14 combinations of mutations were studied, covering a range of no mutations (wild-type $\beta \alpha \gamma-\beta \alpha$ ) to four mutations $[\beta(\mathrm{Y} 143 \mathrm{~W}+\mathrm{M} 286 \mathrm{~W}) \alpha \gamma-\beta(\mathrm{Y} 143 \mathrm{~W}+\mathrm{M} 286 \mathrm{~W}) \alpha]$ (Fig. 1).

To define the number of functional propofol-binding sites present, we mutated residues in these sites separately and together and determined the consequences for activation by propofol. To examine the properties of sites, we analyzed activation properties in receptors containing mutations and inferred the properties of the missing site from the change in the overall functional properties of the receptor. We used four approaches to examine the number of sites: two used measures of the free energy of activation by propofol, and two used estimates of the stoichiometry for activation. The data show that the mutations predominantly act by reducing gating efficacy for propofol. Tryptophan substitutions at $\beta$ (Y143) and $\beta$ (M286) were energetically similar (on average, 1.3 and 0.9 $\mathrm{kcal} / \mathrm{mol}$ per mutation, respectively). By modifying four putative sites, with two $\beta(\mathrm{Y} 143 \mathrm{~W})$ and two $\beta(\mathrm{M} 286 \mathrm{~W})$ mutations, the stabilization energy provided by propofol was reduced from 6.1 to $1.6 \mathrm{kcal} / \mathrm{mol}$. The data suggest that there may be additional functional binding sites for propofol on the receptor.

\section{Materials and Methods}

Constructs and Expression of Receptors. The experiments were conducted on concatemeric rat $\mathrm{GABA}_{\mathrm{A}}$ receptors consisting of a three-subunit $\beta 2 \alpha 1 \gamma 2 \mathrm{~L}$ construct (abbreviated as $\beta \alpha \gamma$ ) and a twosubunit $\beta 2 \alpha 1$ construct (abbreviated as $\beta \alpha$ ). The constructs contain the named individual subunits joined with $23-26$ residue-long linkers. Generation and functional properties of wild-type concatemeric receptors and linker sequences have been reported previously (Bracamontes and Steinbach, 2009; Bracamontes et al., 2011). Mutant clones used here [combinations of $\beta 2(\mathrm{Y} 143 \mathrm{~W}), \beta 2(\mathrm{Y} 205 \mathrm{~S})$,

\section{A}

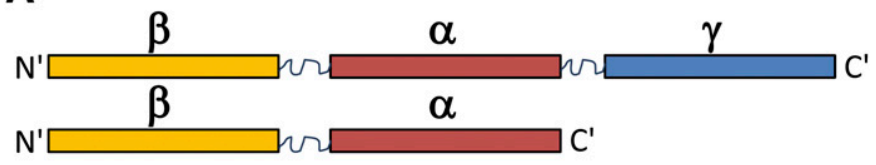

B

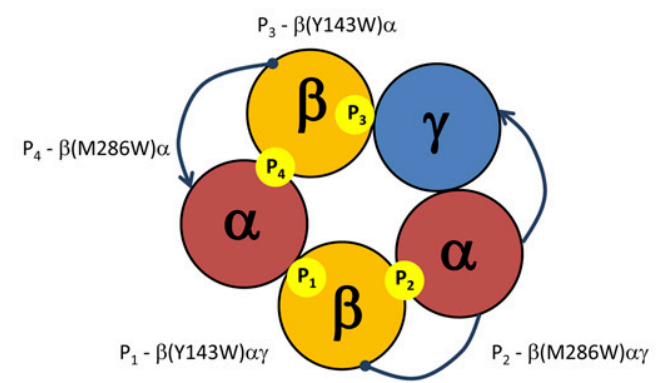

Fig. 1. Structure of concatemeric constructs. (A) Receptors were formed by combining $\beta 2-\alpha 1-\gamma 2 \mathrm{~L}(\beta \alpha \gamma)$ and $\beta 2-\alpha 1(\beta \alpha)$ concatemeric constructs. (B) The presumed assembly order of the constructs is (counterclockwise, viewed from the top) $\beta \alpha \gamma \beta \alpha$ (Baumann et al., 2002). Modifications were made by the $\beta$ (Y143W) mutation, which is located in the $\beta$ subunit at the interface between the extracellular and membrane-spanning domains and is expected to influence propofol interactions with the $\alpha-\beta$ and $\gamma-\beta$ interfaces (sites $\mathrm{P}_{1}$ and $\mathrm{P}_{3}$ ), and the $\beta(\mathrm{M} 286 \mathrm{~W})$ mutation, which is located at the "+" side of the $\beta$ subunit and modifies the two $\beta$ - $\alpha$ interfaces (sites $\mathrm{P}_{2}$ and $\mathrm{P}_{4}$ ). Molecular structures of the putative propofol binding sites at various interfaces have been reported previously (Jayakar et al., 2014; Franks, 2015; Eaton et al., 2016). $\beta 2(\mathrm{M} 286 \mathrm{~W})$, and $\alpha 1$ (L263S)] were generated using QuikChange (Agilent Technologies, Santa Clara, CA). Throughout the manuscript, the numbering used for $\beta 2$ subunit mutations follows the $\beta 3$ numbering for consistency with previous work; the true positions in the mature rat peptide are $\beta 2$ (Y142), $\beta 2$ (Y204), and $\beta 2(\mathrm{M} 285)$. The regions containing the coding sequence for subunits were fully sequenced. The cDNAs were subcloned into the pcDNA3 vector in the $\mathrm{T} 7$ orientation and linearized by digestion with $\mathrm{XbaI}$ (NEB Laboratories, Ipswich, MA). The cRNAs were produced using mMessage mMachine (Ambion, Austin, TX).

The presumed assembly order for the constructs is $\beta \alpha \gamma \beta \alpha$ (counterclockwise, viewed from the top) (Baumann et al., 2002). Each interface is composed of a contribution from two subunits, as schematized in Fig. 1. The $\beta 2(\mathrm{Y} 143 \mathrm{~W})$ mutation is expected to influence the postulated binding site at the "-" side of the $\beta 2$ subunit, and the $\beta 2(\mathrm{M} 286 \mathrm{~W})$ mutation alters the "+" side of the $\beta 2$ subunit. Accordingly, the substitution at M286 is expected to affect propofol interactions with the $\beta$ - $\alpha$ interface and the substitution at Y143 propofol interactions with the sites near the $\alpha-\beta$ and $\gamma-\beta$ interfaces.

Oocytes from Xenopus laevis were injected with a total of 18-20 ng of cRNA in a final volume of 30-60 nl, and incubated in ND96 $(96 \mathrm{mM}$ $\mathrm{NaCl}, 2 \mathrm{mM} \mathrm{KCl}, 1.8 \mathrm{mM} \mathrm{CaCl}_{2}, 1 \mathrm{mM} \mathrm{MgCl}_{2}, 2.5 \mathrm{mM}$ Na pyruvate, $100 \mathrm{U} / \mathrm{ml}$ penicillin, $100 \mu \mathrm{g} / \mathrm{ml}$ streptomycin, $50 \mu \mathrm{g} / \mathrm{ml}$ gentamycin, $5 \mathrm{mM}$ HEPES; $\mathrm{pH} 7.4$ ) at $16^{\circ} \mathrm{C}$. The ratio of cRNAs used for injection was 1:1 $(\beta \alpha \gamma: \beta \alpha)$. The oocytes were used within 2-4 days after injection.

Incorporation of the constructs in surface receptor complexes was shown through effects of introduced mutations on function. In addition, the presence of the $\gamma$ subunit was shown by testing each construct combination for potentiation by diazepam. Coapplication of $1 \mu \mathrm{M}$ diazepam with an $\mathrm{EC}_{5-15}$ concentration of GABA resulted in 2- to 4-fold potentiation (data not shown); this was interpreted as successful incorporation of the $\gamma$ subunit and, consequently, the $\beta \alpha \gamma$ construct. We have previously shown, using Western blotting, that the $\beta \alpha \gamma$ and $\beta \alpha$ concatemeric constructs are not degraded after expression in oocytes (Bracamontes et al., 2011).

Electrophysiological Experiments. All experiments were conducted using a standard two-electrode voltage clamp. Voltage and current electrodes were regular borosilicate patch-clamp electrodes $(\mathrm{G} 120 \mathrm{~F}-4$, outer diameter $=1.20 \mathrm{~mm}$, inner diameter $=0.69 \mathrm{~mm}$; Warner Instruments, Hamden, CT) that, when filled with $3 \mathrm{M}$ $\mathrm{KCl}$, had resistance of less than $1 \mathrm{M} \Omega$. The oocytes were clamped at $-60 \mathrm{mV}$. The chamber (RC-1Z; Warner Instruments) was perfused continuously with bath solution $(92.5 \mathrm{mM} \mathrm{NaCl}, 2.5 \mathrm{mM} \mathrm{KCl}, 1 \mathrm{mM}$

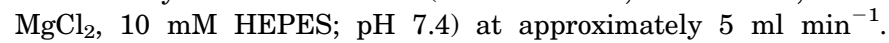
Solutions were gravity-applied from $30-\mathrm{ml}$ glass syringes with glass luer slips via Teflon tubing to reduce adsorption. A typical experiment consisted of recording of a 10-second baseline, followed by a 20-60second drug application, and then a bath application (up to 10 minutes) until recovery. Solutions were switched manually. Duration of drug application depended on the nature of drug and its concentration, and was aimed at reaching a saturated peak response.

Concentration-response relationships for activation were determined by exposing an oocyte to increasing concentrations of agonist (propofol or GABA). The concentration steps were four per decade (1, 2, 5,10 , etc.,) for propofol and three per decade for $\operatorname{GABA}(1,3,10$, etc.) to reflect the differences in Hill slopes (2-3 for propofol, 1-2 for GABA) and to maintain a similar number of concentration points per full concentration-response relationship.

Current responses were amplified with an OC-725C (Warner Instruments) or Axoclamp 900A amplifier (Molecular Devices, Sunnyvale, CA), filtered at $40 \mathrm{~Hz}$, digitized with a Digidata 1200 or 1320 series digitizer (Molecular Devices) at a $100-\mathrm{Hz}$ sampling rate, and stored using pClamp (Molecular Devices). The traces were subsequently analyzed with Clampfit (Molecular Devices) to determine the maximal amplitude of current response.

Descriptive Data Analysis. Descriptive characterization of receptor activity was conducted by determining concentration-response 
relationships for activation by propofol. Activation concentrationresponse curves were fitted, individually for data from each cell, with the following equation:

$$
\mathrm{Y}=\mathrm{Y}_{\max } \times \frac{[\text { agonist }]^{\mathrm{n}_{\mathrm{H}}}}{[\text { agonist }]^{\mathrm{n}_{\mathrm{H}}}+\mathrm{EC}_{50^{\mathrm{n}_{\mathrm{H}}}}}
$$

where $\mathrm{EC}_{50}$ is the concentration of agonist (propofol or GABA) producing a half-maximal effect, $\mathrm{n}_{\mathrm{H}}$ is the Hill slope, and $\mathrm{Y}_{\max }$ is the high concentration asymptote.

Curve-fitting was carried out using Origin version 7.5 (OriginLab, Northhampton, MA) to obtain estimates for $\mathrm{EC}_{50}$ and $\mathrm{n}_{\mathrm{H}}$ separately for data from each cell. Fitting results are reported as arithmetic mean \pm S.E.M (95\% confidence limits; number of cells).

At high concentrations, propofol blocks current responses (Adodra and Hales, 1995). This effect manifests as a reduced initial peak response followed by a more prominent tail or rebound response upon termination of drug application. The rebound response reflects transient repopulation of conducting state(s) of the channel that occurs during washout of the drug. The amplitude of the rebound response was used in curve fitting when it was greater than the initial peak response because it more correctly reflects the fraction of active receptors.

Statistical analyses were performed using Excel (Microsoft, Redmond, WA) or Stata/IC (StataCorp LP, College Station, TX).

Determination of Channel Open Probability. The initial propofol concentration-response data and response amplitudes were converted from current response amplitude into units of open probability. This is done by matching the relative peak responses against a scale ranging from an estimated open probability $\left(\mathrm{P}_{\mathrm{open}}^{\text {est }}\right)$ of $0-1$ (Forman and Stewart, 2012; Eaton et al., 2016). P $\mathrm{P}_{\text {open }}^{\text {est }} 0$ was determined by exposing an oocyte to $500 \mu \mathrm{M}$ [receptors containing the $\alpha 1$ (L263S) mutation] or $100 \mu \mathrm{M}$ (all others) picrotoxin, which resulted in blockade of the constitutive current. A higher concentration of picrotoxin was used with $\alpha 1$ (L263S) because this mutation shifts the picrotoxin inhibition curve to higher concentrations (Chang and Weiss, 1999). A current level corresponding to a $\mathrm{P}_{\mathrm{open}}^{\mathrm{est}}$ of 1 was determined by activating the receptors with a saturating concentration of GABA in the presence of $100 \mu \mathrm{M}$ pentobarbital (Ziemba and Forman, 2016). In cases where no potentiation was observed in the presence of pentobarbital, such as for receptors containing the gain-offunction $\alpha 1$ (L263S) mutation, the receptor was considered to have a $\mathrm{P}_{\mathrm{open}}^{\text {est }}$ indistinguishable from 1 in the presence of saturating GABA alone (Chang and Weiss, 1999; Rüsch and Forman, 2005). Estimated constitutive open probability ( $\mathrm{P}_{\text {open, }}^{\text {est }}$ const $)$ was determined by comparing the holding current in the absence of any compounds active at the $\mathrm{GABA}_{\mathrm{A}}$ receptor to the current level at $\mathrm{P}_{\mathrm{open}}^{\mathrm{est}}=0$ (i.e., in the presence of picrotoxin) and the peak current at $\mathrm{P}_{\mathrm{open}}^{\mathrm{est}}=1$. The maximal open probability elicited by propofol $\left(\mathrm{P}_{\text {open, max }}\right)$ was determined from the ratio of the maximal response to propofol relative to that for GABA, normalized by the maximal $P_{\text {open }}$ for GABA. Values for $P_{\text {open, const }}^{\text {est }}$ and $\mathrm{P}_{\text {open, max }}$ were obtained for each cell and pooled for all cells expressing a given set of constructs. The values are given as arithmetic mean \pm S.E.M. (95\% confidence limits; number of observations).

We use the term estimated open probability for experimentally determined values rather than open probability because of the potential errors associated with this approach. These are incomplete blockade of spontaneous activity in the presence of picrotoxin resulting in overestimated holding current associated with zero activity, and underestimated true current amplitude in response to saturating GABA and a potentiator due to, for example, fast desensitization.

Compliance with Requirements for Studies Using Animals. Oocytes from the African clawed frog (X. laevis) were used for expression of $\mathrm{GABA}_{\mathrm{A}}$ receptors. Oocytes are a widely used and standard expression system for recombinant receptor channels. Their use permits studies of a defined population of receptors to provide specific and reliable pharmacological information. Frogs were purchased from Xenopus 1 (Dexter, MI) and were housed and cared for in a Washington University Animal Care Facility under the supervision of the Washington University Division of Comparative Medicine. Harvesting of oocytes was conducted in accordance with the Guide for the Care and Use of Laboratory Animals as adopted and promulgated by the National Institutes of Health. Oocytes were harvested from mature female frogs under tricaine anesthesia. Oocytes were harvested twice per frog. Frogs were euthanized under tricaine anesthesia by rapid decapitation. The protocol is approved by the Animal Studies Committee of Washington University in St. Louis (approval no. 20140150).

Chemicals and Drugs. Inorganic salts used in buffers, GABA, pentobarbital, and picrotoxin were purchased from Sigma-Aldrich (St. Louis, MO). Propofol was purchased from MP Biomedicals (Solon, OH). Stock solution of GABA was made in bath solution at $500 \mathrm{mM}$, stored in aliquots at $-20^{\circ} \mathrm{C}$, and diluted as needed on the day of the experiment. Stock solutions of propofol [200 $\mathrm{mM}$ in dimethylsulfoxide (DMSO)] and pentobarbital ( $5 \mathrm{mM}$ in bath solution) were kept at room temperature.

The maximal final DMSO concentration in working solutions was $0.5 \%$. We have previously found that $0.5 \% \mathrm{DMSO}$ is without effect on holding current or peak amplitude of the response to an $\mathrm{EC}_{50}$ concentration of GABA from oocytes expressing the closely related $\alpha 1 \beta 3 \gamma 2 \mathrm{~L}$ receptors (Germann et al., 2016).

\section{Results}

Effects of Mutations on Activation by Propofol. We determined the concentration-response relationship for activation by propofol for the various receptors, and fit the concentration-response curves with eq. 1 to obtain estimates of the $\mathrm{EC}_{50}$ and $\mathrm{n}_{\mathrm{H}}$, the Hill coefficient. The results are given in Table 1. The amplitude of the current response to propofol was converted to an estimate of the probability of being open $\left(\mathrm{P}_{\mathrm{open}}^{\mathrm{est}}\right)$ as described in Materials and Methods. Using these values we converted the activation curve for propofol to units of probability of being open, and obtained estimates of $\mathrm{P}_{\text {open, }}$ const for the receptor in the absence of agonists and $\mathrm{P}_{\text {open, max }}$ for propofol. Sample currents and concentration-response relationships are given in Fig. 2.

The first approach to estimating the number of functional binding sites for propofol was to calculate the free-energy change available for channel activation when a saturating concentration of propofol is applied. The basic idea is that, if a $\beta 2(\mathrm{Y} 143 \mathrm{~W})$ or $\beta 2(\mathrm{M} 286 \mathrm{~W})$ mutation reduces the number of functional sites, then there would be an associated reduction in the ability of propofol to cause channel activation. To do this, we analyzed the probability that a channel is open in the absence of any drug and the maximal probability of being open in the presence of propofol. From these probabilities, we computed the ratio of the fraction of channels open to the fraction of channels closed $\left[\mathrm{O} / \mathrm{C}=\mathrm{P}_{\text {open }} /\left(1-\mathrm{P}_{\text {open }}\right)\right]$ in the absence of agonist $\left[(\mathrm{O} / \mathrm{C})_{\text {const }}\right]$ and at the maximal response to propofol $\left[(\mathrm{O} / \mathrm{C})_{\max }\right]$. The logarithm of the ratio $(\mathrm{O} / \mathrm{C})_{\max } /$ $(\mathrm{O} / \mathrm{C})_{\text {const }}$ is proportional to the free energy provided by propofol to stabilize the open state when all available binding sites are occupied by propofol $\left[\Delta \mathrm{G}_{\mathrm{P}}=\mathrm{RT} \ln \left((\mathrm{O} / \mathrm{C})_{\max } /\right.\right.$ $\left.\left.(\mathrm{O} / \mathrm{C})_{\text {const }}\right)\right]$. As shown in Fig. 3A, there was a close to linear $\left(R^{2}=0.907, P=6.2 \mathrm{E}-6\right)$ decline in $\Delta \mathrm{G}_{\mathrm{P}}$ as the number of mutated residues was increased $(-0.87 \pm 0.09 \mathrm{kcal} / \mathrm{mol}$ per mutation) (best estimate for the parameter \pm estimated S.E. provided by the fitting program). That is, each $\beta 2$ (Y143W) or $\beta 2(\mathrm{M} 286 \mathrm{~W})$ mutation results in the loss of a similar energetic contribution to gating. Although this similarity could result from a variety of combinations of numbers of sites with varying energetic contributions, the simplest explanation is that each mutation removes one binding site, and that each 


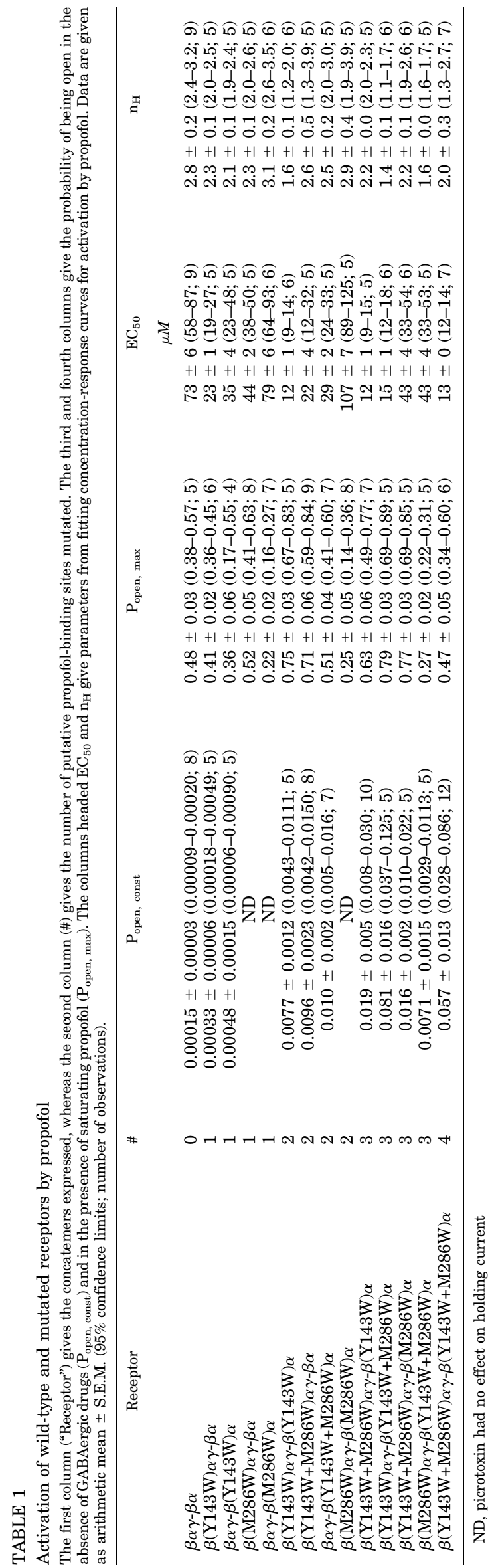

site makes a similar energetic contribution. The linear regression line extrapolates to a total loss of stabilization energy when between five and six energetically equivalent mutations would have been made. If the tryptophan mutations at Y143 or M286 completely remove the ability of propofol to bind and activate, this would suggest that there are five or six functionally equivalent propofolbinding sites. The 95\% confidence interval intersects the abscissa at values of about five and about seven mutations (Fig. 3A).

We also examined the relationship between the Hill coefficient and the number of introduced mutations. As shown in Fig. 3B, there is a steady decline in the estimated value of $\mathrm{n}_{\mathrm{H}}$ with increasing numbers of mutations (linear regression slope $=-0.28$ /mutation). The relationship between $\mathrm{n}_{\mathrm{H}}$ and the actual number of functional sites involved in activation is not direct, and $\mathrm{n}_{\mathrm{H}}$ represents a minimal number of binding sites. Accordingly the relationship between $\mathrm{n}_{\mathrm{H}}$ and the number of mutations is not a reliable indicator of the stoichiometry of activation, and the observation that the fitted regression reaches a predicted value of 1 after 6.5 mutations does not imply that the stoichiometry of activation for wild-type receptors is actually seven (or more). Still, the observation that the Hill coefficient was statistically significantly greater than 1 even after four mutations were introduced (1.72 $\pm 0.13, N=5, P=0.012$ that the difference from 1 arises from random sampling error by a one-sample $t$ test) supports the idea that more than five sites are present. The $95 \%$ confidence interval intersects the line for a Hill coefficient of 1 at values of about 4 and about 28 mutations (Fig. 3B).

These data support the idea that the $\beta 2(\mathrm{Y} 143 \mathrm{~W})$ and $\beta 2(\mathrm{M} 286 \mathrm{~W})$ mutations reduce the number of propofolbinding sites on the $\mathrm{GABA}_{\mathrm{A}}$ receptor. Furthermore, there are likely to be five or six functional sites on the receptor.

The Number of Propofol-Binding Sites from the Stabilization Energy for the Open State. To analyze the data more fully, and to characterize the properties of the sites, we next analyzed the data in terms of a simple cyclic kinetic model, initially proposed by Monod et al. (1965). In the first analysis using the model (Fig. 4A; Monod et al., 1965; Karlin, 1967), we determined the stabilization energy provided by propofol. The experimental concentrationresponse curves for activation by propofol were fit with eq. 2 (Chang and Weiss, 1999; Rüsch et al., 2004):

$$
\mathrm{P}^{\text {open est }}=\frac{1}{1+\mathrm{L}_{0} \times\left[\frac{1+[\text { propofol }] / K_{\mathrm{P}}}{1+[\text { propofol }] / c_{\mathrm{P}} K_{\mathrm{P}}}\right]^{N_{\mathrm{P}}}}
$$

where $\mathrm{L}_{0}$ is the gating equilibrium constant for unliganded receptors, $K_{\mathrm{P}}$ is the closed-receptor equilibrium dissociation constant for propofol, and $N_{\mathrm{P}}$ corresponds to the number of propofol-binding sites. Parameter $c_{\mathrm{P}}$ reflects the gating efficacy conferred by the relative affinity of GABA for open and closed channels and is expressed as the ratio of openreceptor dissociation constant to closed-receptor dissociation constant.

In performing the fits, we constrained the value for $\mathrm{L}_{0}$ to the value calculated from the experimentally determined constitutive open probability $\left(\mathrm{P}_{\text {open, const }}\right)$, where $\mathrm{L}_{0}=\left(1-\mathrm{P}_{\text {open, const }}\right) / \mathrm{P}_{\text {open, const. Alternatively, when }}$ 
A
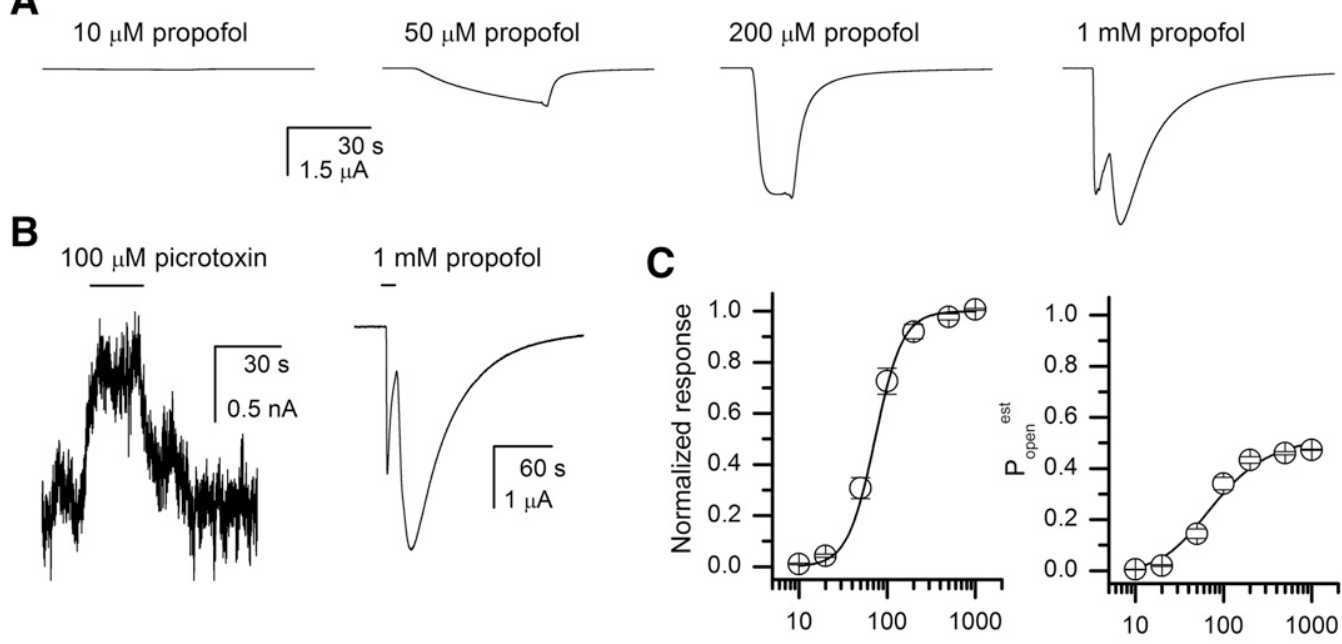

[Propofol] $(\mu \mathrm{M})$

Fig. 2. Activation of the $\beta \alpha \gamma-\beta \alpha$ receptor by propofol. (A) Sample current traces from an oocyte injected with $\beta \alpha \gamma$ and $\beta \alpha$ concatemeric constructs and exposed to $10 \mu \mathrm{M}$ to $1 \mathrm{mM}$ propofol. The response to $1 \mathrm{mM}$ propofol shows an initial peak response followed by a larger rebound response upon removal of propofol. The amplitude of the rebound response was used in curve fitting. (B) Changes in holding current in the presence of $100 \mu \mathrm{M}$ picrotoxin. The second trace shows a reference response to saturating $(1 \mathrm{mM})$ propofol from the same oocyte. (C) Propofol concentration-response relationships. The left panel shows data normalized to the maximal fitted response. The data points show the mean \pm S.E.M. from six cells. The curve was simulated using eq. 1 and the mean $\mathrm{EC}_{50}$ and $\mathrm{n}_{\mathrm{H}}$ values provided in Table 1. The right panel shows data plotted as estimated open probability. The curve was generated using eq. 2. The $K_{\mathrm{P}}$ and $c_{\mathrm{P}}$ values associated with the fit are given in Table 2.

$\mathrm{P}_{\text {open, const }}$ could not be reliably directly measured, $\mathrm{L}_{0}$ was calculated from the effect of the gain-of-function $\alpha 1$ (L263S) mutation using the following equation:

$$
\mathrm{L}_{0}=\mathrm{L}_{0, \mathrm{~L} 263 \mathrm{~S}}\left(\mathrm{EC}_{50, \mathrm{GABA}} / \mathrm{EC}_{50, \mathrm{GABA}, \mathrm{L} 263 \mathrm{~S}}\right)^{1.76}
$$

where $\mathrm{L}_{0}$ and $\mathrm{EC}_{50, \mathrm{GABA}}$ apply to the receptor of interest, and $\mathrm{L}_{0}$, L263S and $\mathrm{EC}_{50}$, GABA, L263S apply to a receptor additionally containing the $\alpha 1$ (L263S) mutation. Equation 3 is modified from previous versions (Karlin, 1967; Rüsch and Forman, 2005 ), in which the exponent was given the value 2 (the number of binding sites for GABA), based on a more complete analysis of the relationship between $\mathrm{EC}_{50}$ and $\mathrm{L}$ (Akk et al., 2017). Substitution of $\alpha 1$ (L263) ( $9^{\prime}$ in the second membranespanning domain) with a polar residue such as serine or threonine has been shown to increase constitutive activity and shift the agonist concentration-response profile to lower concentrations through changes in gating efficacy (Chang et al., 1996; Scheller and Forman, 2002).

We also constrained the number of binding sites by assuming that the wild-type $\beta \alpha \gamma-\beta \alpha$ receptor has six binding sites for propofol $\left(N_{\mathrm{P} \text {, wt }}=6\right)$, and that each mutation removed one binding site so, for example, the receptor formed from $\beta(\mathrm{Y} 143 \mathrm{~W}+\mathrm{M} 286 \mathrm{~W}) \alpha \gamma-\beta(\mathrm{Y} 143 \mathrm{~W}+\mathrm{M} 286 \mathrm{~W}) \alpha \quad$ concatemers contained only two sites $\left(N_{\mathrm{P}}\right.$, mut $\left.=2\right)$. The concentration-response curves for activation by propofol were then fit to obtain estimates for $c_{\mathrm{P}}$ and $K_{\mathrm{P}}$ (Table 2).

The total energy stabilizing the open state when all propofol-binding sites are occupied is $\Delta \mathrm{G}_{\mathrm{P}}=N_{\mathrm{P}} \mathrm{RT} \ln \left(c_{\mathrm{P}}\right)$. Figure 4 shows the change in stabilization energy as a function of the number of mutations introduced. The linear regression has a slope of $-0.95 \pm 0.13 \mathrm{kcal} / \mathrm{mol}$ per mutation $\left(R^{2}=0.81\right.$, $P=1.1 \times 10^{-5}$ ), whereas the line intersects the abscissa at 5.9 mutations. This relationship is similar to that seen in the analysis of the $\mathrm{O} / \mathrm{C}$ ratios, and again is consistent with the idea that there are five or six equivalent propofol-binding sites on the wild-type receptor. The $95 \%$ confidence interval intersects the abscissa at values of about 5 and about 8 mutations (Fig. 4). We also fitted the data with an assumed value of $N_{\mathrm{P}, \mathrm{wt}}=$ 5 with similar results (slope $=-0.94 \pm 0.13$, abscissal intercept 6.0; data not shown). Again, the interpretation that five or six functional sites are present is based on the assumption that the tryptophan mutation completely removes the contribution of that site, as stated earlier.

The Number of Propofol-Binding Sites Estimated from the Relationship between the $\mathbf{E C}_{50}$ for Propofol and the Basal Activity of the Receptor. Karlin (1967) first pointed out that the $\mathrm{EC}_{50}$ for an agonist acting according to an Monod-Wyman-Changeux (MWC) kinetic scheme depends on the basal activity of the receptor and on the number of binding sites for the agonist. Accordingly, we used this relationship to examine the number of propofol-binding sites.

We changed the basal activity in two ways. We altered the activity in the absence of added GABAergic agents by mutating the receptor, and we added an orthosteric agonist (that acted at a different site from the propofol-binding site). If a second activator (B) is present that does not bind to the same site as propofol, eq. 2 becomes:

$$
\mathrm{P}^{\text {open est }}=\frac{1}{1+\mathrm{L}_{0} \times\left[\frac{1+[\text { propofol }] / K_{\mathrm{P}}}{1+[\text { propofol }] / c_{\mathrm{P}} K_{\mathrm{P}}}\right]^{N_{\mathrm{P}}}\left[\frac{1+[\mathrm{B}] / K_{\mathrm{B}}}{1+[\mathrm{B}] / c_{\mathrm{B}} K_{\mathrm{B}}}\right]^{N_{\mathrm{B}}}}
$$

where $K_{\mathrm{B}}$ is the dissociation constant for agonist B binding to its site when the receptor is in the closed state, $c_{\mathrm{B}}$ is the ratio of the dissociation constants for binding of $B$ in the open state to that in the closed state, $N_{\mathrm{B}}$ is the number of sites for B, and other terms are as defined earlier.

Inspection of eq. 4 indicates that, in the presence of a constant concentration of agonist $B$, the effects of $B$ on responses to propofol can be understood simply as a change in the value of the ratio of closed to open receptors: 
A

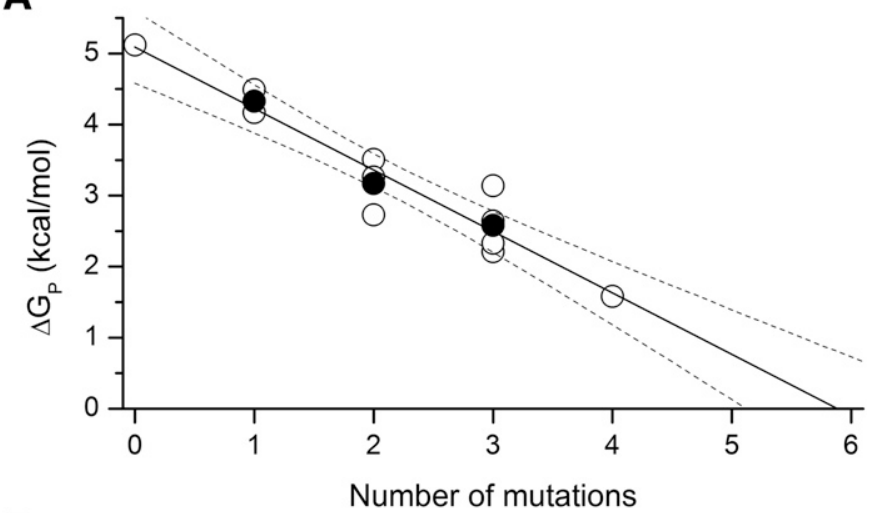

B

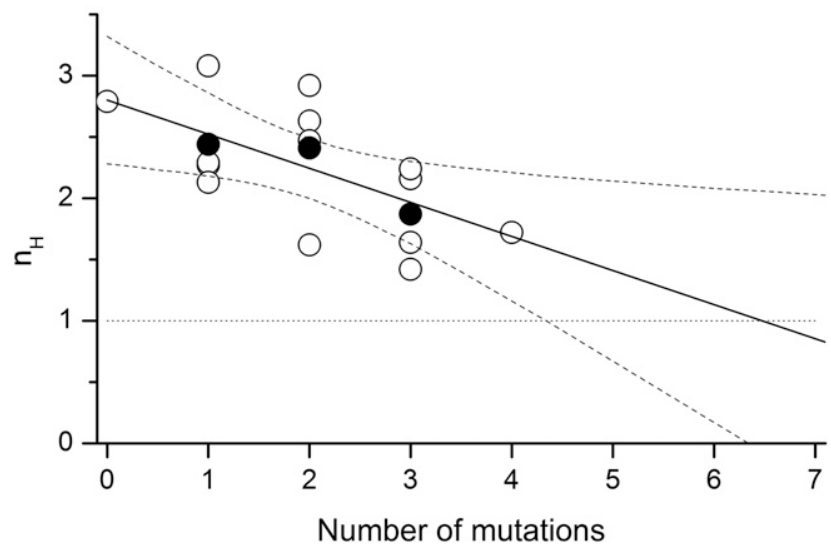

Fig. 3. Relationship between the activation parameters and number of mutations. (A) The total energy contributed by propofol to stabilize the open state of the receptor $\left(\Delta \mathrm{G}_{\mathrm{P}}=\mathrm{RT} \ln \left[(\mathrm{O} / \mathrm{C})_{\max } /(\mathrm{O} / \mathrm{C})_{\text {const }}\right]\right)$ is plotted against the total number of $\beta 2(\mathrm{Y} 143 \mathrm{~W})$ or $\beta 2(\mathrm{M} 286 \mathrm{~W})$ mutations in the receptor (mean values shown as solid symbols). The solid line shows the linear regression of $\Delta \mathrm{G}_{\mathrm{P}}$ on the number of mutations, with the $95 \%$ confidence limits shown by dashed lines. The slope of the regression line is $-0.87 \pm 0.09 \mathrm{kcal} / \mathrm{mol}$ per mutation (best estimate for the parameter \pm estimated S.E. provided by the fitting program; $R^{2}=0.91 ; P$ value for the hypothesis that the slope is actually zero $=6 \times 10^{-6}$ ), and the line intersects the abscissa at 5.9 mutations, suggesting there might be five or six functionally equivalent sites in total. The 95\% confidence lines intersect at values of 5.12 and 7.10 mutations. (B) The value of the Hill coefficient fit to propofol activation curves is plotted against the total number of mutations in the receptor. The linear regression is shown by the solid line with the $95 \%$ confidence limits shown by the dashed lines. The slope of the regression line is $-0.28 \pm 0.11$ per mutation $\left(R^{2}=0.37 ; P\right.$ value for the hypothesis that the slope is actually zero $=0.02$ ). The line intersects the line for a Hill coefficient equal to 1 at 6.5 mutations, suggesting there might be between seven and eight functional sites in total. The 95\% confidence lines intersect at values of 4.34 and 28.2 mutations.

$$
\mathrm{L}_{\mathrm{B}}=\mathrm{L}_{0} \times\left[\frac{1+[\mathrm{B}] / K_{\mathrm{B}}}{1+[\mathrm{B}] / c_{\mathrm{B}} K_{\mathrm{B}}}\right]^{N_{\mathrm{B}}}
$$

where $\mathrm{L}_{\mathrm{B}}$ is the modified $\mathrm{C} / \mathrm{O}$ ratio reflecting the change in basal activity due to the presence of agonist $\mathrm{B}$. This equation explains the relationship between activation by one compound (agonist B) and the ability of $\mathrm{B}$ to potentiate responses to another agonist. This relationship has been investigated and supported for the $\mathrm{GABA}_{\mathrm{A}}$ receptor in a series of papers (Rüsch et al., 2004; Ruesch et al., 2012).

In the kinetic model used, the $\mathrm{EC}_{50}$ for activation of a receptor by an agonist normalized to its affinity to the activated receptor is given by the following equation (Karlin, 1967):
A

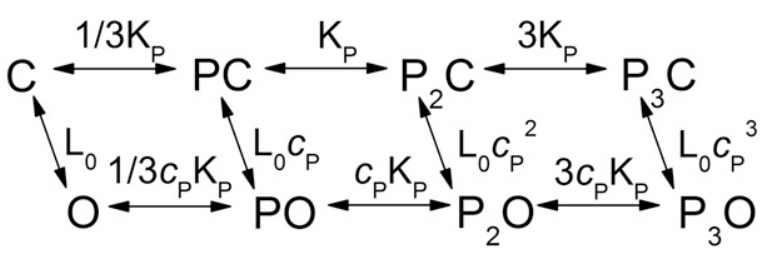

B

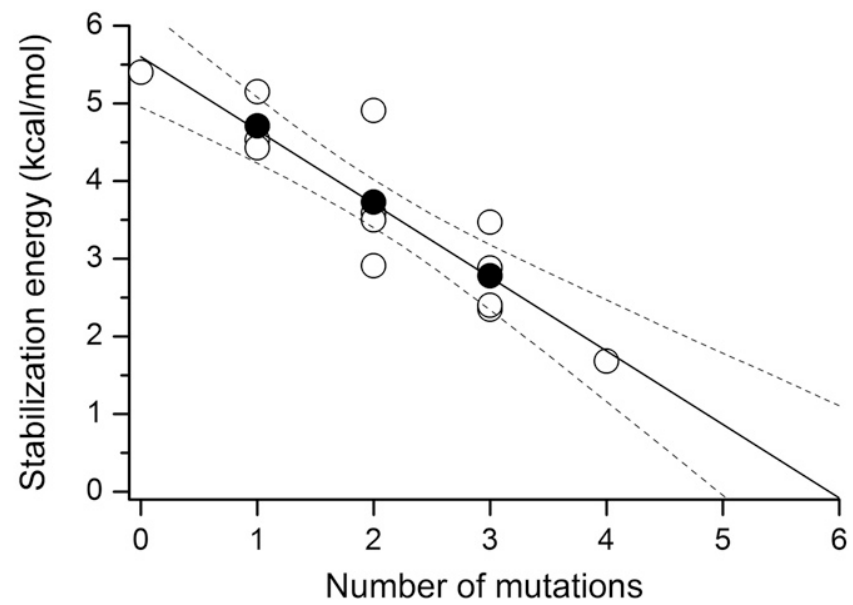

Fig. 4. Analysis of receptor activation using the Monod-WymanChangeux coagonist model. (A) The receptor in the absence of activator is in equilibrium between $\mathrm{C}$ (closed) and $\mathrm{O}$ (open), described by $\mathrm{L}_{0}(\mathrm{C} / \mathrm{O})$. Propofol (P) binds to three equivalent sites with an equilibrium dissociation constant of $K_{\mathrm{P}}$. Related models with different numbers of propofolbinding sites $\left(N_{\mathrm{P}}\right)$ would have $N_{\mathrm{P}}+1$ horizontally added layers. (B) The value of the total stabilization energy contributed by propofol $\left[\Delta \mathrm{G}_{\mathrm{P}}=N_{\mathrm{P}} \times\right.$ $\left.\mathrm{RT} \ln \left(c_{\mathrm{P}}\right)\right]$ is plotted against the total number of $\beta 2(\mathrm{Y} 143 \mathrm{~W})$ or $\beta 2(\mathrm{M} 286 \mathrm{~W})$ mutations in the receptor (mean values shown as solid symbols). The values for $c_{\mathrm{P}}$ were obtained assuming the $N_{\mathrm{P} \text {, wT }}=6$, and $N_{\mathrm{P} \text {, mut }}=6-$ number of mutations. The linear regression is shown by the solid line with the $95 \%$ confidence limits shown by the dashed lines. The slope of the regression line is $-0.95 \pm 0.13 \mathrm{kcal} / \mathrm{mol}$ per mutation (best estimate for the parameter \pm estimated S.E. provided by the fitting program; $R^{2}=0.81 ; P$ value for hypothesis that slope is actually zero $=1.1 \times 10^{-5}$ ). The line intersects the abscissa at 5.9 mutations. The $95 \%$ confidence lines intersect at values of 4.96 and 7.67 mutations. The data values are shown in Table 2 .

$$
\mathrm{EC}_{50} /(c \mathrm{~K})=\frac{\left(2+\mathrm{L}+\mathrm{L} c^{\mathrm{N}}\right)^{1 / \mathrm{N}}-\left(1+c^{\mathrm{N}}+2 \mathrm{~L} c^{\mathrm{N}}\right)^{1 / \mathrm{N}}}{\left(1+c^{\mathrm{N}}+2 \mathrm{~L} c^{\mathrm{N}}\right)^{1 / \mathrm{N}}-c\left(2+\mathrm{L}+\mathrm{L} c^{\mathrm{N}}\right)^{1 / \mathrm{N}}}
$$

where $\mathrm{L}$ denotes $\mathrm{C} / \mathrm{O}$ (either $\mathrm{L}_{0}$ or $\mathrm{L}_{\mathrm{B}}$ ) and is calculated as $\mathrm{L}=$ $\left(1-\mathrm{P}_{\text {open, basal }}\right) / \mathrm{P}_{\text {open, basal }}$, with $\mathrm{P}_{\text {open, basal }}$ reflecting activity in the absence of any agonist or in the presence of a constant concentration of an agonist acting at a different site (i.e., agonist B).

To determine whether eq. 6 provides an adequate description of activation of receptors by propofol, we examined the effect of changes in basal activity on the measured $\mathrm{EC}_{50}$ for propofol $\left(\mathrm{EC}_{50}, \mathrm{P}\right)$. Figure 5 shows the relationships between $\mathrm{EC}_{50, \mathrm{p}}$ and $\mathrm{L}$ for wild-type receptors, and for receptors containing mutations that are not predicted to affect values for $N_{\mathrm{P}}, K_{\mathrm{P}}$, or $c_{\mathrm{P}}$. The basal activity for wild-type receptors was changed by two agonists at the GABA-binding site (GABA and $\mathrm{P} 4 \mathrm{~S})$. The predictions of eq. 6 are very close to the experimentally measured data (Fig. 5A).

We tested the effects of two mutations that are not expected to affect activation parameters for propofol (Fig. 5B). The 
TABLE 2

Parameters for activation by propofol obtained by fitting concentration-response curves with predictions from the MWC model

The first column gives the concatemers expressed, whereas the second column gives the number of proposed propofol-binding sites mutated. The column headed $\mathrm{L}_{0}$ gives the ratio $\mathrm{P}_{\text {closed }} / \mathrm{P}_{\text {open }}$ for that receptor in the absence of added agonists. Data for $\mathrm{L}_{0}$ are given as arithmetic mean $\pm \mathrm{S} . \mathrm{E} . \mathrm{M}$ (95\% confidence limits; number of observations). The $\mathrm{P}_{\text {open, }}$ const for wild-type $\beta \alpha \gamma-\beta \alpha$ receptors would give an estimate of $\mathrm{L}_{0}=8676 \pm 1429(n=8)$ In other cases, $\mathrm{L}_{0}$ was estimated from the effect of picrotoxin on currents in the absence of other drugs. $N_{\mathrm{P}}$ is the number of propofol-binding sites assumed in performing the fits (see Materials and Methods); for these values, it was assumed that the wild-type $\beta \alpha \gamma-\beta \alpha$ receptor has $N_{\mathrm{Prop}}=6$. $c_{\mathrm{P}}$ gives the ratio of the affinity of propofol to the open-channel to that for the closed-channel forms of the receptor. $K_{\mathrm{P}}$ gives the affinity of propofol for the closed-channel form of the receptor. The values for $c_{\mathrm{P}}$ and $K_{\mathrm{P}}$ are given as best estimate for the parameter \pm estimated S.E. provided by the fitting program (Origin v. 7.5).

\begin{tabular}{|c|c|c|c|c|c|}
\hline Receptor & \# & $\mathrm{L}_{0}$ & $N_{\mathrm{P}}$ & $c_{\mathrm{P}}$ & $K_{\mathrm{P}}(\mu M)$ \\
\hline$\beta \alpha \gamma-\beta \alpha$ & 0 & $9000^{a}$ & 6 & $0.22 \pm 0.003$ & $21 \pm 3$ \\
\hline$\beta(\mathrm{Y} 143 \mathrm{~W}) \alpha \gamma-\beta \alpha$ & 1 & $3425 \pm 680(1539-5312 ; 5)$ & 5 & $0.20 \pm 0.003$ & $9.0 \pm 1.1$ \\
\hline$\beta \alpha \gamma-\beta(\mathrm{Y} 143 \mathrm{~W}) \alpha$ & 1 & $2722 \pm 540(1223-4221 ; 5)$ & 5 & $0.22 \pm 0.004$ & $13 \pm 2$ \\
\hline$\beta(\mathrm{M} 286 \mathrm{~W}) \alpha \gamma-\beta \alpha$ & 1 & $1457 \pm 305(672-2242 ; 6)^{b}$ & 5 & $0.22 \pm 0.004$ & $17 \pm 3$ \\
\hline$\beta \alpha \gamma-\beta(\mathrm{M} 286 \mathrm{~W}) \alpha$ & 1 & $17,083 \pm 5940(1813-32,354 ; 6)$ & 5 & $0.17 \pm 0.005$ & $24 \pm 6$ \\
\hline$\beta(\mathrm{Y} 143 \mathrm{~W}) \alpha \gamma-\beta(\mathrm{Y} 143 \mathrm{~W}) \alpha$ & 2 & $141 \pm 20(85-198 ; 5)$ & 4 & $0.21 \pm 0.005$ & $9.0 \pm 0.9$ \\
\hline$\beta(\mathrm{Y} 143 \mathrm{~W}+\mathrm{M} 286 \mathrm{~W}) \alpha \gamma-\beta \alpha$ & 2 & $155 \pm 36(69-241 ; 8)$ & 4 & $0.21 \pm 0.008$ & $18 \pm 3$ \\
\hline$\beta \alpha \gamma-\beta(\mathrm{Y} 143 \mathrm{~W}+\mathrm{M} 286 \mathrm{~W}) \alpha$ & 2 & $123 \pm 22(68-177 ; 7)$ & 4 & $0.28 \pm 0.010$ & $20 \pm 5$ \\
\hline$\beta(\mathrm{M} 286 \mathrm{~W}) \alpha \gamma-\beta(\mathrm{M} 286 \mathrm{~W}) \alpha$ & 2 & $10,475 \pm 1840(6124-14,827 ; 8)^{b}$ & 4 & $0.12 \pm 0.003$ & $37 \pm 8$ \\
\hline$\beta(\mathrm{Y} 143 \mathrm{~W}+\mathrm{M} 286 \mathrm{~W}) \alpha \gamma-\beta(\mathrm{Y} 143 \mathrm{~W}) \alpha$ & 3 & $86 \pm 19(44-129 ; 10)$ & 3 & $0.17 \pm 0.007$ & $13 \pm 2$ \\
\hline$\beta(\mathrm{Y} 143 \mathrm{~W}) \alpha \gamma-\beta(\mathrm{Y} 143 \mathrm{~W}+\mathrm{M} 286 \mathrm{~W}) \alpha$ & 3 & $13 \pm 3(6-20 ; 5)$ & 3 & $0.26 \pm 0.010$ & $21 \pm 2$ \\
\hline$\beta(\mathrm{Y} 143 \mathrm{~W}+\mathrm{M} 286 \mathrm{~W}) \alpha \gamma-\beta(\mathrm{M} 286 \mathrm{~W}) \alpha$ & 3 & $67 \pm 10(41-94 ; 5)$ & 3 & $0.14 \pm 0.010$ & $64 \pm 12$ \\
\hline$\beta(\mathrm{M} 286 \mathrm{~W}) \alpha \gamma-\beta(\mathrm{Y} 143 \mathrm{~W}+\mathrm{M} 286 \mathrm{~W}) \alpha$ & 3 & $163 \pm 27(87-239 ; 5)$ & 3 & $0.24 \pm 0.005$ & $24 \pm 3$ \\
\hline$\beta(\mathrm{Y} 143 \mathrm{~W}+\mathrm{M} 286 \mathrm{~W}) \alpha \gamma-\beta(\mathrm{Y} 143 \mathrm{~W}+\mathrm{M} 286 \mathrm{~W}) \alpha$ & 4 & $13 \pm 1(12-15 ; 11)$ & 2 & $0.29 \pm 0.025$ & $21 \pm 8$ \\
\hline
\end{tabular}

${ }^{a} \mathrm{~L}_{0}$ set to value of 9000

${ }^{b}$ Indicates $\mathrm{L}_{0}$ estimated from picrotoxin effect on a receptor additionally containing the $\alpha(\mathrm{L} 263 \mathrm{~S})$ mutation.

$\beta 2(\mathrm{Y} 205 \mathrm{~S})$ mutation effectively removes one GABA-binding site (Amin and Weiss, 1993). The $\alpha$ (L263S) shifts the opening equilibrium toward the open state without major effects on agonist binding (Chang and Weiss, 1999; Rüsch and Forman, 2005). The effect of GABA on basal activity and $\mathrm{EC}_{50}$, $\mathrm{P}$ was well described even for receptors with a reduced number of GABA-binding sites [ $\beta 2(\mathrm{Y} 205 \mathrm{~S})]$. Equation 6 described the change in $\mathrm{EC}_{50}$, $\mathrm{P}$ resulting from a change in $\mathrm{L}_{0}$ for the $\alpha(\mathrm{L} 263 \mathrm{~S})$ mutation. For receptors containing the $\alpha(\mathrm{L} 263 \mathrm{~S})$ mutation, we used GABA to decrease the $\mathrm{C} / \mathrm{O}$ ratio (reduce $\mathrm{L}$ ) and the antagonist bicuculline to increase $\mathrm{L}$. Bicuculline is both a competitive antagonist at the GABA-binding site and an allosteric antagonist (Ueno et al., 1997; Chang and Weiss, 1999), and is expected to have a $c_{\mathrm{B}}$ value greater than 1 , so that $\mathrm{L}_{\mathrm{B}}>\mathrm{L}_{0}$ (eqs. 4 and 5). Again, eq. 6 predicts the change in $\mathrm{EC}_{50}$, P with changed $\mathrm{L}$ for both GABAergic agents.

The data shown in Fig. 5 (see also Table 3) support the idea that eq. 6 describes the relationship between $\mathrm{EC}_{50}$, $\mathrm{P}$ and $\mathrm{L}$, when $\mathrm{L}$ is changed by mutation or by background activation by
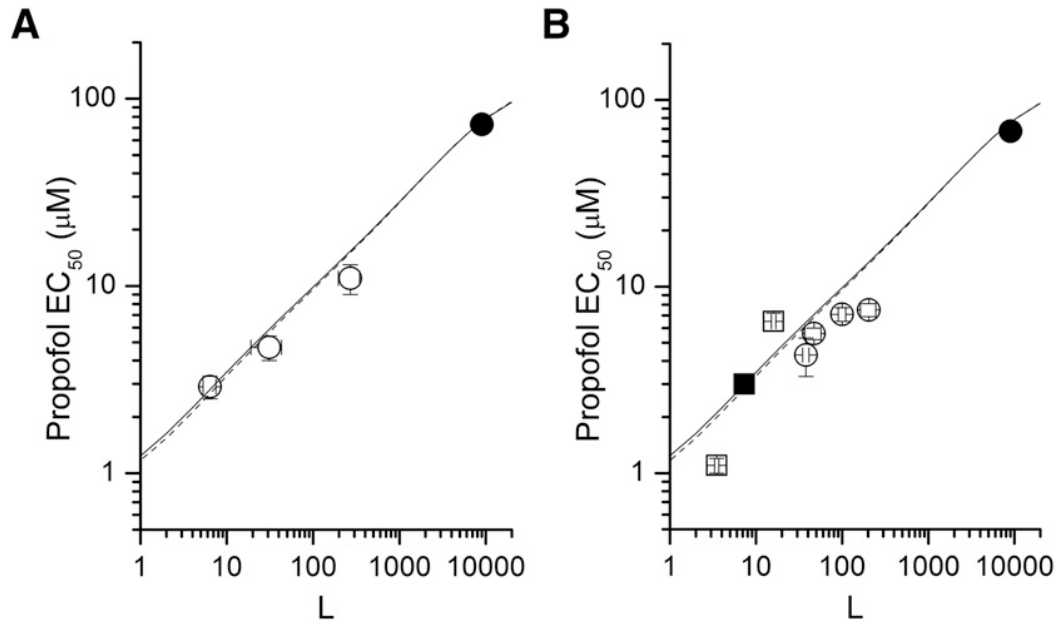

Fig. 5. Relationship between the $\mathrm{EC}_{50}$ for propofol and basal activity. (A) The data for the $\mathrm{EC}_{50}$ for propofol plotted against the value for $\mathrm{L}$ for wild-type receptors in the absence of any other agonist (filled circle) or in the presence of $10 \mu \mathrm{M}$ GABA, $10 \mu \mathrm{M}$ P4S, and $1 \mu \mathrm{M}$ GABA (hollow circles; from lower to higher $\mathrm{L}$ value). The solid line shows the predicted relationship from eq. 2 using the values for $K_{\mathrm{P}}$ and $c_{\mathrm{P}}$ obtained from fitting the concentration-response relationship for wild-type $\beta \alpha \gamma-\beta \alpha$ receptors with $N_{\mathrm{P}}=6$. The dotted line (largely hidden by the solid line) shows the predictions for $N_{\mathrm{P}}=5$. Note that the predicted line describes the data very well when the basal activity level is increased by the addition of two agonists for the GABA-binding site. (B) The data for the $\mathrm{EC}_{50}$ for propofol plotted against the value for $\mathrm{L}$ for receptors containing mutations that are not expected to affect activation parameters for propofol. Filled symbols show data for $\mathrm{EC}_{50}$, in the absence of other drugs. Data for receptors containing the $\beta \alpha \gamma$ and $\beta$ (Y205S) $\alpha$ concatemers are shown as circles; hollow circles show data when background activity was elicited by $20,50,100$, or $1000 \mu \mathrm{M}$ GABA. Data for receptors containing the $\beta \alpha$ (L263S) $\gamma$ $\beta \alpha$ (L263S) concatemers are shown as squares; hollow squares show data when activity was elicited by $0.1 \mu \mathrm{M}$ GABA or reduced by $20 \mu \mathrm{M}$ bicuculline. The lines show the predictions as in (A). The data values are given in Table 3. 
TABLE 3

Data for the $\mathrm{EC}_{50}$ for propofol activation as a function of basal activity of the receptor for wild-type receptors or receptors containing mutations at locations outside of the putative propofol-binding sites

The first column gives the concatemers expressed, whereas the second column gives the background drug used to change the basal activity of the receptor. The column headed $\mathrm{EC}_{50}$ gives the $\mathrm{EC}_{50}$ for propofol activation determined for that level of basal activity, and L gives the ratio $P_{\text {closed }} / P_{\text {open }}$ for that receptor in the presence of the listed background drug. Data are given as arithmetic mean \pm S.E.M. (95\% confidence limits; number of observations). Note that bicuculline reduced the level of spontaneous current (thereby increasing L) as expected for an allosteric antagonist. In other cases, L was estimated from the basal activity in the absence of propofol.

\begin{tabular}{lccc}
\hline \multicolumn{1}{c}{ Receptor } & Background Drug & $\mathrm{EC}_{50}$ & $\mathrm{~L}$ \\
\hline & & $\mu M$ & \\
$\beta \alpha \gamma-\beta \alpha$ & None & $73 \pm 6(58-87 ; 9)$ & 9000 \\
$\beta \alpha \gamma-\beta \alpha$ & $1 \mu \mathrm{M}$ GABA & $11 \pm 2(5-16 ; 5)$ & $270 \pm 74(65-474 ; 5)$ \\
$\beta \alpha \gamma-\beta \alpha$ & $10 \mu \mathrm{M}$ GABA & $2.9 \pm 0.4(1.9-4.0 ; 5)$ & $6.4 \pm 1.1(3.4-9.4 ; 5)$ \\
$\beta \alpha \gamma-\beta \alpha$ & $10 \mu \mathrm{M} \mathrm{P} 4 \mathrm{~S}$ & $4.7 \pm 0.7(2.7-6.7 ; 5)$ & $31 \pm 12(-2$ to $65 ; 5)$ \\
$\beta \alpha(\mathrm{L} 263 \mathrm{~S}) \gamma-\beta \alpha(\mathrm{L} 263 \mathrm{~S})$ & None & $3.0 \pm 0.2(2.3-3.6 ; 5)$ & $7.3 \pm 0.4(6.3-8.3 ; 10)^{a}$ \\
$\beta \alpha(\mathrm{L} 263 \mathrm{~S}) \gamma-\beta \alpha(\mathrm{L} 263 \mathrm{~S})$ & $0.1 \mu \mathrm{M}$ GABA & $1.1 \pm 0.1(0.8-1.3 ; 5)$ & $3.5 \pm 0.2(3.0-4.0 ; 9)$ \\
$\beta \alpha(\mathrm{L} 263 \mathrm{~S}) \gamma-\beta \alpha(\mathrm{L} 263 \mathrm{~S})$ & $20 \mu \mathrm{M}$ bicuculline & $6.5 \pm 0.7(4.5-8.6 ; 5)$ & $16 \pm 1(13-18 ; 5)$ \\
$\beta \alpha \gamma-\beta(\mathrm{Y} 205 \mathrm{~S}) \alpha$ & None & $68 \pm 4(56-80 ; 5)$ & $9000^{b}$ \\
$\beta \alpha \gamma-\beta(\mathrm{Y} 205 \mathrm{~S}) \alpha$ & $20 \mu \mathrm{M}$ GABA & $7.5 \pm 0.6(5.8-9.2 ; 5)$ & $204 \pm 41(90-318 ; 5)$ \\
$\beta \alpha \gamma-\beta(\mathrm{Y} 205 \mathrm{~S}) \alpha$ & $50 \mu \mathrm{M}$ GABA & $7.1 \pm 0.6(5.4-8.8 ; 5)$ & $100 \pm 10(72-128 ; 5)$ \\
$\beta \alpha \gamma-\beta(\mathrm{Y} 205 \mathrm{~S}) \alpha$ & $100 \mu \mathrm{M}$ GABA & $5.6 \pm 0.4(4.4-6.7 ; 5)$ & $47 \pm 10(20-74 ; 5)$ \\
$\beta \alpha \gamma-\beta(\mathrm{Y} 205 \mathrm{~S}) \alpha$ & $1000 \mu \mathrm{M}$ GABA & $4.3 \pm 1.0(1.6-6.9 ; 5)$ & $39 \pm 3(31-47 ; 5)$ \\
\hline
\end{tabular}

${ }^{a} \mathrm{~L}$ estimated from picrotoxin effect on currents in the absence of other drugs.

${ }^{b}$ Indicates that $\mathrm{L}$ was assumed to be unchanged from wild-type $\beta \alpha \gamma-\beta \alpha$ receptors.

drugs that act at a site that is distinct from the propofolbinding site.

Next, we examined the relationship between $\mathrm{EC}_{50}$, p and $\mathrm{L}$ for receptors containing mutations to one or more of the putative propofol-binding sites. In terms of the MWC model, removing one or more propofol-binding sites should not affect the values for $K_{\mathrm{P}}$ or $c_{\mathrm{P}}$ for the remaining sites, so it is possible to predict the relationship between $\mathrm{EC}_{50}$, $\mathrm{P}$ and $\mathrm{L}$ based on the values obtained from fitting the activation of wild-type $\beta \alpha \gamma-\beta \alpha$ receptors, with assumed values for $N_{\mathrm{P}}$ for each mutant and the measured value for $\mathrm{L}$.

The data are shown in Fig. 6 and Table 4. Figure 6A shows data for wild-type $\beta \alpha \gamma-\beta \alpha$ receptors and receptors containing mutations of one to four of the propofol-binding sites, obtained in the absence of other compounds. Figure 6, B-F shows data for receptors containing a given number of binding-site mutations, now including data obtained in the presence of various concentrations of orthosteric agonists to change the value for $L$. Note that as the number of mutations increases (the number of intact propofol-binding sites decreases), characteristic changes occur in the shape of the relationship: the $\mathrm{EC}_{50}$ value for high values of $\mathrm{L}$ decreases while that for low values increases, and the region between the two asymptotic values for the $\mathrm{EC}_{50}$ becomes smaller. As seen in Fig. 6, the predictions describe the data well, based on the predicted numbers of functional propofol-binding sites.

To obtain an estimate of the ability of the predictions to describe the data, we calculated the logarithm of the ratio of the experimentally determined $\mathrm{EC}_{50}$ to the predicted $\mathrm{EC}_{50}$. The logarithm of the ratio was used, rather than the difference between data and prediction, because the values for $\mathrm{EC}_{50}$ extended over a large range, and we wanted to weight the different values more equally. The results are consistent with the idea that a better description is obtained when $N_{\mathrm{P}}$ decreases as the number of mutations increases. When the data were fit with $N_{\mathrm{P}}$ held constant at 6 for both wild-type and mutated receptors, the mean overall logarithmic ratio was $0.15 \pm 0.07$ (95\% confidence limits: $0.01-0.30$; number of observations: 27). In contrast, when $N_{\mathrm{P}}$ was reduced by 1 for each mutation introduced, the mean ratio was $0.04 \pm 0.07$ $(-0.19$ to $0.10 ; 27)$. The difference in means was statistically significant $\left(P<0.9 \times 10^{-6}\right.$ using a two-tailed paired-sample $t$ test).

Values of $N_{\mathrm{P} \text {, wT }}$ from 5 to 12 were used to fit the concentrationresponse data for wild-type $\beta \alpha \gamma-\beta \alpha$ receptors and obtain estimates for $K_{\mathrm{P}}$ and $c_{\mathrm{P}}$. These values were used to calculate predicted $\mathrm{EC}_{50}$ values and $\log \left(\mathrm{EC}_{50 \text {, exp }} / \mathrm{EC}_{50 \text {, pred }}\right)$ using measured values of $\mathrm{L}$ and assuming that $N_{\mathrm{P} \text {, mut }}=N_{\mathrm{P} \text {, wT }}-$ (number of sites mutated). An assumed value of $N_{\mathrm{P} \text {, wT }}=8$ provided the lowest ratio; the mean $\log \left(\mathrm{EC}_{50 \text {, exp }} / \mathrm{EC}_{50 \text {, pred }}\right)=-0.001 \pm 0.067$ (an average ratio of 0.997 ). The mean was lower for $N_{\mathrm{P}}=8$ than for other values tested $(P<0.012$ for all comparisons using a two-tailed paired-sample $t$ test with Bonferroni post-hoc correction).

Overall, the results of an analysis in terms of the MWC model support the idea that there are between 6 and 8 equivalent propofol-binding sites on the wild-type $\beta \alpha \gamma-\beta \alpha$ receptor.

Effects of Mutations on Binding and Gating Properties of Propofol. The analyses indicate that there are several functional binding sites for propofol, with at least two classes of sites identified by the mutations which affect the sites [e.g., the sites affected by the mutation $\beta 2(\mathrm{M} 286 \mathrm{~W})$ and those affected by $\beta 2(\mathrm{Y} 143 \mathrm{~W})]$. We considered the question of whether the properties of the sites differ. We used parameters derived from the MWC analysis; two were properties of the propofol-binding sites $\left(c_{\mathrm{P}}\right.$ and $\left.K_{\mathrm{P}}\right)$, whereas the third was a property of the receptor $\left(\mathrm{L}_{0}\right)$. The numbers for $c_{\mathrm{P}}$ and $K_{\mathrm{P}}$ differ depending on the value for $N_{\mathrm{P}, \mathrm{WT}}$, whereas the data for $\mathrm{L}_{0}$ are independent of $N_{\mathrm{P}}$. The initial data values given are for $N_{\mathrm{P}, \mathrm{wT}}=6$.

Is there a difference in the effect on $c_{\mathrm{P}}$ when $\beta 2(\mathrm{Y} 143)$ is mutated, as compared with $\beta 2$ (M286)? We studied a total of 24 pairs of concatemers in which a single mutation [either $\beta 2(\mathrm{Y} 143 \mathrm{~W})$ or $\beta 2(\mathrm{M} 286 \mathrm{~W})]$ is introduced. For example, the pair $\alpha \beta(\mathrm{Y} 143 \mathrm{~W}) \gamma-\beta \alpha$ to $\alpha \beta(\mathrm{Y} 143 \mathrm{~W}+\mathrm{M} 286 \mathrm{~W}) \gamma-\beta \alpha$ involves introduction of a single $\mathrm{M} 286 \mathrm{~W}$ mutation. The mean change in stabilization energy $(\Delta \Delta G)$ for all pairs was $-0.96 \pm 0.14$ $(-1.24$ to $-0.67 ; 24) \mathrm{kcal} / \mathrm{mol}$ per mutation. When a single $\beta 2(\mathrm{Y} 143 \mathrm{~W})$ was introduced, the mean was $-1.2 \pm 0.2(-1.61$ 
A

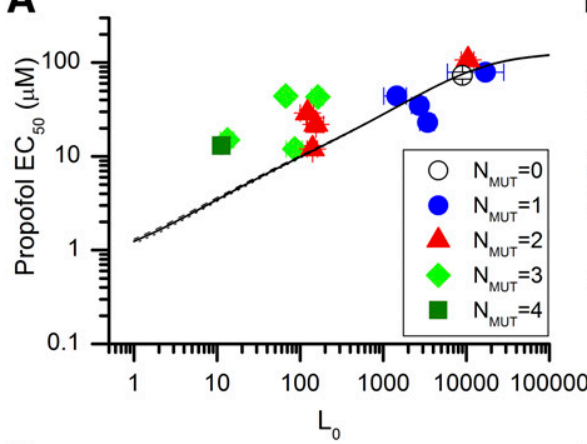

C

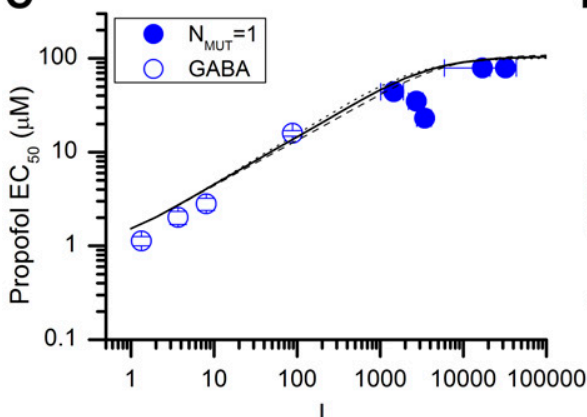

E

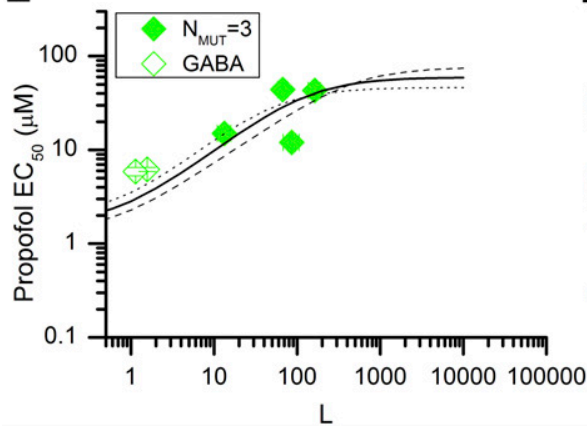

B

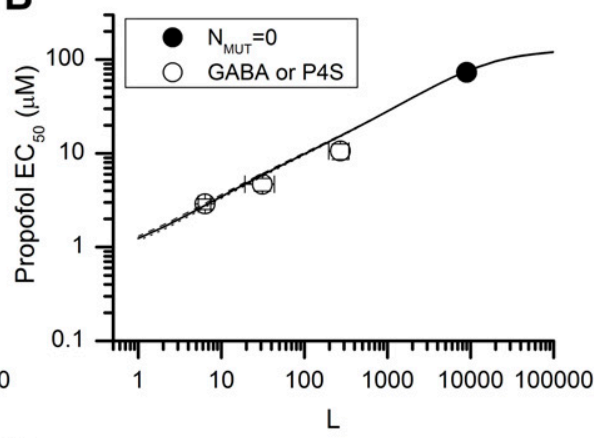

D

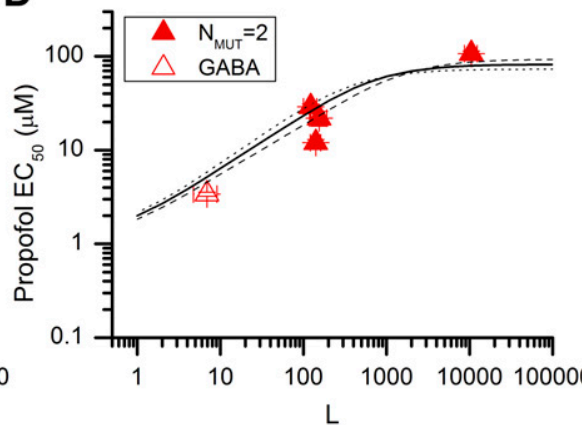

$\mathbf{F}$

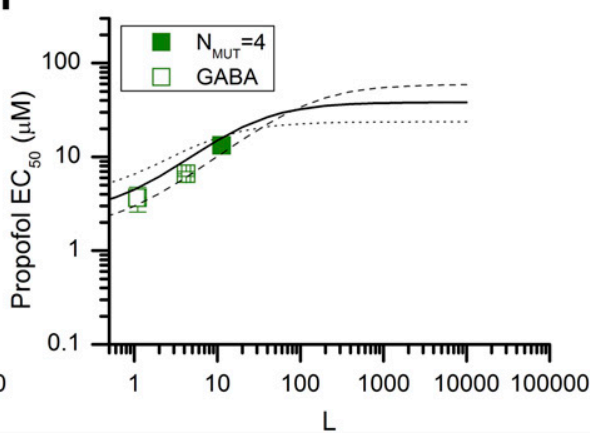

Fig. 6. Effects of mutations on the relationship between the $\mathrm{EC}_{50}$ for propofol and L. (A) Data are shown for all mutations, for constitutive activity. The different symbols identify receptors containing different numbers of mutations, from 0 (wildtype) to four mutations of propofol-binding sites. The remaining panels show data separately for no mutations of propofol-binding sites (B), mutations of one site (C), two sites (D), three sites (E), and four sites (F). In each panel, filled symbols show data for different combinations of mutations, whereas hollow symbols show data when a drug active at the GABA-binding site was used to alter L. The lines show predictions made using parameters obtained from fits to concentrationresponse data for activation by propofol of the wild-type $\beta \alpha \gamma-\beta \alpha$ receptors with $N_{\mathrm{P}}=5$ (dotted line), 6 (solid line), or 8 (dashed line). The predictions for $N_{\mathrm{P}}=8$ are shown because that assumed value gave the smallest value for the sum of the logarithms of the ratio $\mathrm{EC}_{50 \text {, exp }} / \mathrm{EC}_{50}$, pred (see text). The data values are in Table 4. to $-0.79 ; 12) \mathrm{kcal} / \mathrm{mol}$, and when a single $\beta 2(\mathrm{M} 286 \mathrm{~W})$ was introduced, it was $-0.7 \pm 0.2(-1.11$ to $-0.32 ; 12) \mathrm{kcal} / \mathrm{mol}$ per mutation. The difference in effect between the two types of mutations was not statistically significant ( $P$ for the difference was 0.11 by Wilcoxon rank-sum test). There also were no differences depending on the location of the mutation in either concatemer or on the background construct (i.e., whether there was already a mutation in one or the other concatemer), indicating that the sites contribute independently to channel activation by propofol. Indistinguishable results were obtained when the data were fit with $N_{\mathrm{P} \text {, wT }}=5$ or 8 : the global mean values for either assumed value of $N_{\mathrm{P}}$, wT are also $-1.0 \pm 0.1 \mathrm{kcal} / \mathrm{mol}$ per mutation, and the mean for addition of one $\mathrm{Y} 143 \mathrm{~W}$ is $-1.2 \pm 0.2$ and for $\mathrm{M} 286 \mathrm{~W}$ is $-0.7 \pm$ 0.2 .

It is also possible to analyze the energetic changes from the changes in the ratio $(\mathrm{O} / \mathrm{C})_{\max } /(\mathrm{O} / \mathrm{C})_{\text {const }}$, as described earlier. We could not determine $(\mathrm{O} / \mathrm{C})_{\text {const }}$ for all constructs since picrotoxin had no measurable effect on holding current for some, so only 16 pairs of receptors differed by a single mutation. In this analysis, the consequences of adding a single Y143W or M286W mutation were indistinguishable: addition of one $\mathrm{Y} 143 \mathrm{~W}$ resulted in $\Delta \Delta \mathrm{G}=-0.83 \pm 0.12(0.55$ to $1.11 ; 8)$ $\mathrm{kcal} / \mathrm{mol}$, whereas one $\mathrm{M} 286 \mathrm{~W}$ resulted in $-0.88 \pm 0.16(0.49$ to $1.27 ; 8)$.

We next turned to the second property of the sites for propofol, $K_{\mathrm{P}}$. The linear regression of $K_{\mathrm{P}}$ versus the number of mutations had a slope of $3.6 \pm 3.6 \mu \mathrm{M}$ per mutation $\left(R^{2}=\right.$ $0.08)$, so there was no significant relationship between the overall number of mutations and $K_{\mathrm{P}}$. The mean ratio of the $K_{\mathrm{P}}$ values for the pairs of receptors with a single added mutation was $1.1 \pm 0.2(0.60-1.42 ; 24)$, which did not differ from 1 ( $P=$ $0.6)$. However, when the relationship was separated out into the two types of mutation, a pattern emerged. When $\beta 2(\mathrm{Y} 143 \mathrm{~W})$ is introduced, on average, $K_{\mathrm{P}}$ decreases [mean $0.8 \pm 0.1(0.60-1.06 ; 12)$, whereas for a single $\beta 2(\mathrm{M} 286 \mathrm{~W}), K_{\mathrm{P}}$ increases $[1.7 \pm 0.2(1.24-2.17 ; 12)]$. The two ratios $\operatorname{differ}(P=$ 0.0012 by a Wilcoxon rank-sum test). The changes when mutations are introduced indicate that the site affected by the $\beta 2(\mathrm{M} 286 \mathrm{~W})$ mutation has a lower $K_{\mathrm{P}}$ than the site affected by $\beta 2(\mathrm{Y} 143 \mathrm{~W})$. Removal of one type of site (e.g., by Y143W) reveals the properties of the other site (in this case, the site affected by M286W) for the actions of propofol, so it is likely that the site defined by M286 has a $K_{\mathrm{P}}$ about half that of the Y143 site (from the ratio of the relative changes). Analysis of the magnitude of the change with respect to the concatemer 
TABLE 4

Data for the $\mathrm{EC}_{50}$ for propofol activation as a function of basal activity of the receptor for wild-type receptors or receptors containing mutations at the putative propofol-binding sites

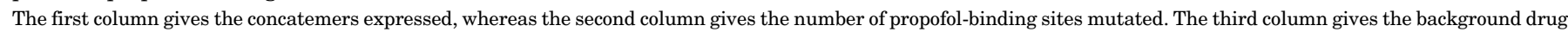

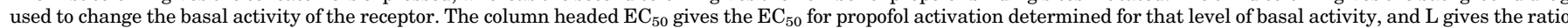

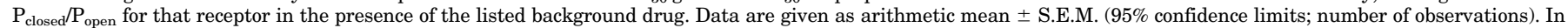
other cases, L was estimated from the current elicited by the background drug.

\begin{tabular}{|c|c|c|c|c|}
\hline Receptor & \# & Background Drug & $\mathrm{EC}_{50}$ & $\mathrm{~L}$ \\
\hline & \multicolumn{4}{|c|}{$\mu M$} \\
\hline$\beta \alpha \gamma-\beta \alpha$ & 0 & None & $73 \pm 6(58-87 ; 9)$ & $9000^{\alpha}$ \\
\hline$\beta \alpha \gamma-\beta \alpha$ & 0 & $1 \mu \mathrm{M}$ GABA & $11 \pm 2(5-16 ; 5)$ & $270 \pm 74(65-474 ; 5)$ \\
\hline$\beta \alpha \gamma-\beta \alpha$ & 0 & $10 \mu \mathrm{M}$ GABA & $2.9 \pm 0.4(1.9-4.0 ; 5)$ & $6.4 \pm 1.1(3.4-9.4 ; 5)$ \\
\hline$\beta \alpha \gamma-\beta \alpha$ & 0 & $10 \mu \mathrm{M}$ P4S & $4.7 \pm 0.7(2.7-6.7 ; 5)$ & $31 \pm 12(-2$ to $65 ; 5)$ \\
\hline$\beta(\mathrm{Y} 143 \mathrm{~W}) \alpha \gamma-\beta \alpha$ & 1 & None & $23 \pm 1(19-27 ; 5)$ & $3425 \pm 680(1539-5312 ; 5)^{b}$ \\
\hline$\beta(\mathrm{Y} 143 \mathrm{~W}) \alpha \gamma-\beta \alpha$ & 1 & $1 \mu \mathrm{M}$ GABA & $2.8 \pm 0.4(1.7-3.9 ; 5)$ & $8.1 \pm 0.8(5.9-10.2 ; 5)$ \\
\hline$\beta(\mathrm{Y} 143 \mathrm{~W}) \alpha \gamma-\beta \alpha$ & 1 & $3 \mu \mathrm{M}$ GABA & $1.1 \pm 0.1(0.8-1.5 ; 5)$ & $1.3 \pm 0.2(0.9-1.8 ; 5)$ \\
\hline$\beta \alpha \gamma-\beta(\mathrm{Y} 143 \mathrm{~W}) \alpha$ & 1 & None & $35 \pm 4(23-48 ; 5)$ & $2722 \pm 540(1223-4221 ; 5)^{b}$ \\
\hline$\beta \alpha \gamma-\beta(\mathrm{Y} 143 \mathrm{~W}) \alpha$ & 1 & $0.1 \mu \mathrm{M}$ GABA & $16 \pm 1(13-19 ; 5)$ & $88 \pm 13(51-125 ; 5)$ \\
\hline$\beta \alpha \gamma-\beta(\mathrm{Y} 143 \mathrm{~W}) \alpha$ & 1 & $1 \mu \mathrm{M}$ GABA & $2.0 \pm 0.3(1.1-2.9 ; 5)$ & $3.7 \pm 0.3(2.8-4.6 ; 5)$ \\
\hline$\beta(\mathrm{M} 286 \mathrm{~W}) \alpha \gamma-\beta \alpha$ & 1 & None & $44 \pm 5(31-58 ; 5)$ & $1457 \pm 305(672-2242 ; 6)$ \\
\hline$\beta \alpha \gamma-\beta(\mathrm{M} 286 \mathrm{~W}) \alpha$ & 1 & None & $79 \pm 6(64-93 ; 6)$ & $17,083 \pm 5940(1813-32,354 ; 6)^{c}$ \\
\hline$\beta(\mathrm{Y} 143 \mathrm{~W}) \alpha \gamma-\beta(\mathrm{Y} 143 \mathrm{~W}) \alpha$ & 2 & None & $12 \pm 1(9-14 ; 6)$ & $141 \pm 20(85-198 ; 5)^{b}$ \\
\hline$\beta(\mathrm{Y} 143 \mathrm{~W}+\mathrm{M} 286 \mathrm{~W}) \alpha \gamma-\beta \alpha$ & 2 & None & $22 \pm 4(12-32 ; 5)$ & $155 \pm 36(69-241 ; 8)^{b}$ \\
\hline$\beta(\mathrm{Y} 143 \mathrm{~W}+\mathrm{M} 286 \mathrm{~W}) \alpha \gamma-\beta \alpha$ & 2 & $1 \mu \mathrm{M}$ GABA & $3.4 \pm 0.2(2.9-3.9 ; 5)$ & $6.9 \pm 2.2(0.9-13.0 ; 5)$ \\
\hline$\beta \alpha \gamma-\beta(\mathrm{Y} 143 \mathrm{~W}+\mathrm{M} 286 \mathrm{~W}) \alpha$ & 2 & None & $29 \pm 2(24-33 ; 5)$ & $123 \pm 22(68-177 ; 7)^{b}$ \\
\hline$\beta(\mathrm{M} 286 \mathrm{~W}) \alpha \gamma-\beta(\mathrm{M} 286 \mathrm{~W}) \alpha$ & 2 & None & $107 \pm 7(89-125 ; 5)$ & $10,475 \pm 1840(6124-14,827 ; 8)$ \\
\hline$\beta(\mathrm{Y} 143 \mathrm{~W}+\mathrm{M} 286 \mathrm{~W}) \alpha \gamma-\beta(\mathrm{Y} 143 \mathrm{~W}) \alpha$ & 3 & None & $12 \pm 1(9-15 ; 5)$ & $86 \pm 19(44-129 ; 10)^{b}$ \\
\hline$\beta(\mathrm{Y} 143 \mathrm{~W}+\mathrm{M} 286 \mathrm{~W}) \alpha \gamma-\beta(\mathrm{Y} 143 \mathrm{~W}) \alpha$ & 3 & $0.3 \mu \mathrm{M}$ GABA & $6.2 \pm 0.3(5.4-6.9 ; 5)$ & $1.6 \pm 0.1(1.3-1.8 ; 5)$ \\
\hline$\beta(\mathrm{Y} 143 \mathrm{~W}) \alpha \gamma-\beta(\mathrm{Y} 143 \mathrm{~W}+\mathrm{M} 286 \mathrm{~W}) \alpha$ & 3 & None & $15 \pm 1(12-18 ; 6)$ & $13 \pm 3(6-20 ; 5)^{b}$ \\
\hline$\beta(\mathrm{Y} 143 \mathrm{~W}+\mathrm{M} 286 \mathrm{~W}) \alpha \gamma-\beta(\mathrm{M} 286 \mathrm{~W}) \alpha$ & 3 & None & $43 \pm 4(33-54 ; 6)$ & $67 \pm 10(41-94 ; 5)^{b}$ \\
\hline$\beta(\mathrm{Y} 143 \mathrm{~W}+\mathrm{M} 286 \mathrm{~W}) \alpha \gamma-\beta(\mathrm{M} 286 \mathrm{~W}) \alpha$ & 3 & $1 \mu \mathrm{M}$ GABA & $5.9 \pm 0.6(4.2-7.6 ; 5)$ & $1.1 \pm 0.1(0.9-1.3 ; 5)$ \\
\hline$\beta(\mathrm{M} 286 \mathrm{~W}) \alpha \gamma-\beta(\mathrm{Y} 143 \mathrm{~W}+\mathrm{M} 286 \mathrm{~W}) \alpha$ & 3 & None & $43 \pm 4(33-53 ; 5)$ & $163 \pm 27(87-239 ; 5)^{b}$ \\
\hline$\beta(\mathrm{Y} 143 \mathrm{~W}+\mathrm{M} 286 \mathrm{~W}) \alpha \gamma-\beta(\mathrm{Y} 143 \mathrm{~W}+\mathrm{M} 286 \mathrm{~W}) \alpha$ & 4 & None & $13 \pm 1(12-15 ; 6)$ & $11 \pm 2(6-16 ; 12)^{b}$ \\
\hline$\beta(\mathrm{Y} 143 \mathrm{~W}+\mathrm{M} 286 \mathrm{~W}) \alpha \gamma-\beta(\mathrm{Y} 143 \mathrm{~W}+\mathrm{M} 286 \mathrm{~W}) \alpha$ & 4 & $0.03 \mu \mathrm{M}$ GABA & $6.6 \pm 0.4(5.6-7.7 ; 5)$ & $4.2 \pm 0.5(2.8-5.6 ; 5)$ \\
\hline$\beta(\mathrm{Y} 143 \mathrm{~W}+\mathrm{M} 286 \mathrm{~W}) \alpha \gamma-\beta(\mathrm{Y} 143 \mathrm{~W}+\mathrm{M} 286 \mathrm{~W}) \alpha$ & 4 & $0.1 \mu \mathrm{M}$ GABA & $3.7 \pm 1.1(-1.0$ to $8.3 ; 3)$ & $1.1 \pm 0.2(0.6-1.7 ; 6)$ \\
\hline
\end{tabular}

${ }^{a} \mathrm{~L}_{0}$ set to value of 9000 . The $\mathrm{P}_{\mathrm{o} \text {,const }}$ for wild-type $\beta \alpha \gamma-\beta \alpha$ receptors would give an estimate of $\mathrm{L}_{0}=8676 \pm 1429(n=8)$.

${ }^{b} \mathrm{~L}_{0}$ estimated from picrotoxin effect on currents in the absence of other drugs.

${ }^{c} \mathrm{~L}$ estimated from picrotoxin effect on a receptor additionally containing the $\alpha$ (L263S) mutation (see Materials and Methods).

that was mutated or the presence of additional mutations in the subunits did not reveal any correlation (data not shown). Again, the results were similar when values of $N_{\mathrm{P}, \mathrm{WT}}=5$ or 8 were used: for mutations of $\mathrm{Y} 143, K_{\mathrm{P}}$ was reduced $(0.96 \pm$ 0.14 for $N_{\mathrm{P}, \mathrm{WT}}=5$ and $0.8 \pm 0.1$ for $\left.N_{\mathrm{P}, \mathrm{WT}}=8\right)$ in contrast to the effects of mutations to M286 $\left(2.0 \pm 0.3\right.$ for $N_{\mathrm{P}, \mathrm{WT}}=$ 5 and $1.6 \pm 0.2$ for $\left.N_{\mathrm{P}, \mathrm{WT}}=8\right)$, and the changes in $K_{\mathrm{P}}$ differed for the mutations $\left(P<0.001\right.$ for each). Changes in $\mathrm{EC}_{50}$ are not readily interpretable, as the $\mathrm{EC}_{50}$ reflects affinity and efficacy. Accordingly, no attempt was made to analyze these data.

Finally, we considered the effects of mutations on the basal activity in the absence of drugs, $\mathrm{L}_{0}$. $\mathrm{L}_{0}$ is a property of the receptor itself, not of the drugs that act on it, and so does not depend on $N_{\mathrm{P}}$. The linear regression of $\Delta \mathrm{G}$ for $\mathrm{L}_{0}$ on the number of mutations was $-1.1 \pm 0.2 \mathrm{kcal} / \mathrm{mol}$ per mutation $\left(R^{2}=0.60 ; P=5 \times 10^{-5}\right)$, indicating that the effect on $\mathrm{L}_{0}$ scales with the total number of mutations. Again we determined the effect on $\mathrm{L}_{0}$ depending on whether a single $\beta 2(\mathrm{Y} 143 \mathrm{~W})$ or $\beta 2(\mathrm{M} 286 \mathrm{~W})$ mutation occurred. The mean $\Delta \Delta \mathrm{G}$ for $\mathrm{L}_{0}$ upon introduction of a single $\beta 2(\mathrm{Y} 143 \mathrm{~W})$ mutation was $1.6 \pm 0.3(1.02-2.12 ; 12) \mathrm{kcal} / \mathrm{mol}$, whereas for the introduction of $\beta 2(\mathrm{M} 286 \mathrm{~W})$, it was $0.5 \pm 0.3(-0.02$ to $1.15 ; 12)$ ( $P$ for the $\Delta \Delta \mathrm{G}$ being identical is 0.02 by a Wilcoxon rank-sum test). One possible basis for an effect on $\mathrm{L}_{0}$ is that the introduction of a tryptophan side chain mimics the binding of propofol to its site. In this case, it might be expected that there would be a correlation between the effect of a mutation on the change in the total stabilization energy (decreased by the mutation) and the effect on spontaneous activity (increased by the mutation). There is a relationship between $\Delta \Delta \mathrm{G}$ for $\mathrm{L}_{0}$ and for $c_{\mathrm{P}}$ for these 24 pairs, as shown in Fig. 7. The slope of a linear regression of $\Delta \Delta \mathrm{G}$ for $\mathrm{L}_{0}$ on $\Delta \Delta \mathrm{G}$ for $c_{\mathrm{P}}$ is $-1.2 \pm 0.2\left(P=7 \times 10^{-6}\right)$. The intercept $(-0.06 \pm 0.2)$ is not statistically significantly different from $0(P=0.8)$. Again, similar results were obtained when values of $N_{\mathrm{P}, \mathrm{wT}}=5$ or 8 were used: the slopes were -1.2 \pm 0.2 and $-1.2 \pm 0.2$ and the intercepts were $-0.01 \pm 0.2$ and $-0.07 \pm 0.2$, respectively. The observation that the slope of the relationship is close to unity suggests that, indeed, the insertion of a tryptophan at these locations comes close to mimicking the binding of propofol. As would be expected, the regression of $\Delta \mathrm{G}$ values calculated from $(\mathrm{O} / \mathrm{C})_{\text {const }}$ over the ratio $(\mathrm{O} / \mathrm{C})_{\max } /(\mathrm{O} / \mathrm{C})_{\text {const }}$ was also similar (slope $-1.1 \pm 0.1$, intercept $0.4 \pm 0.4$ ).

\section{Discussion}

Our goals were to gain insight into the number of functionally apparent propofol-binding sites on $\mathrm{GABA}_{\mathrm{A}}$ receptors comprising $\alpha, \beta$, and $\gamma$ subunits, and to assess the properties of the sites. We used four approaches to estimate the number of functional sites: two used measures of the free energy contributed to channel activation by propofol binding. Both approaches supported the conclusion that five or six sites are present, based on the number of functionally equivalent mutations predicted to fully remove the effect of propofol. It must be emphasized that both approaches assumed that the 


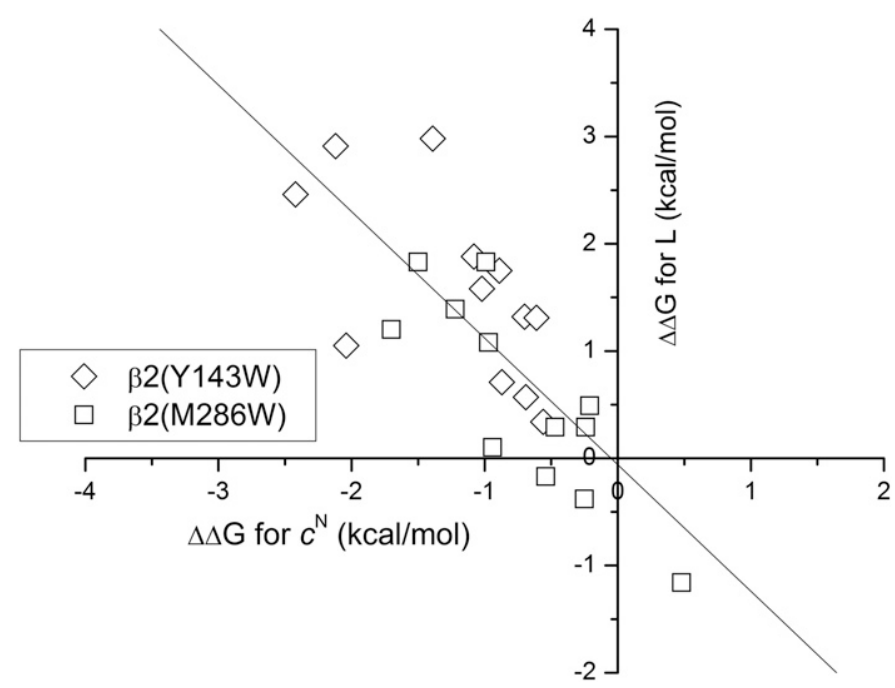

Fig. 7. The relationship between constitutive activity and stabilization energy contributed by propofol. The value for the change in energy for constitutive gating is plotted against the change in stabilization energy contributed by propofol binding for 24 pairs of receptors in which a single mutation was introduced. The linear regression slope is $-1.2 \pm 0.2\left(R^{2}=\right.$ $0.60 ; P$ value for hypothesis that slope is actually zero $=8 \times 10^{-6}$ ). The slope for the $\beta 2(\mathrm{Y} 143 \mathrm{~W})$ mutations is $-0.9 \pm 0.3$, and that for the $\beta 2(\mathrm{M} 286 \mathrm{~W})$ mutations is $-1.2 \pm 0.3$; the slopes do not differ $(P=0.4)$.

tryptophan mutation fully ablates the energetic contribution of propofol binding. If there were a residual effect of propofol binding, then this approach would artifactually estimate a larger number of predicted sites than were actually present (we discuss this more later). However, our observations indicate that mutation of each of four proposed propofolbinding sites has a functional effect, so the minimal number of functionally apparent sites is four.

The other two approaches estimated the stoichiometry for activation by propofol, first by using the Hill coefficient determined by fitting the concentration-activation curves for propofol. We used linear extrapolation to estimate that the Hill coefficient would be reduced to a value of 1 when 6.5 mutations had been made, suggesting that there were between seven and eight sites on the receptor. The Hill coefficient is only an indirect reflection of the number of bound agonist molecules required for activation, and in general, the number of activation sites is greater than the Hill coefficient. Still, the observation that the Hill coefficient was greater than 1 even after all four sites were mutated supports the idea that more than four sites are present. However, again it is the case that if the mutations only partially removed the ability of propofol to activate, then the Hill coefficient would change in complicated ways, but likely would remain above 1 even if all sites were altered.

The final approach used the predicted relationship between the $\mathrm{EC}_{50}$ for activation by propofol and the level of basal activity of the receptor. The shape of the relationship depends on the number of propofol-binding sites, which we changed by mutations of the four known sites. In control manipulations, we altered basal activity by using drugs active at the GABAbinding site or by mutations that increase constitutive activity, and found that the changes in $\mathrm{EC}_{50}$ as a function of changes in basal activity were well described by the predictions. Mutations of propofol-binding sites changed the relationship, and analysis of the changes indicated that the assumption of eight propofol sites in the wild-type receptor provided the best description.

The various approaches to estimating the numbers of functionally present sites for propofol activation of $\mathrm{GABA}_{\mathrm{A}}$ receptors indicate that all four of the sites identified by photolabeling and mutagenesis are demonstrably active, and that each site acts independently of the other sites. The data suggest that there are one or two additional functionally equivalent sites. The major caveat to the existence of additional sites is the uncertainty introduced by the possibility that the tryptophan mutation may not completely prevent propofol activation mediated by that site. Our data do not resolve this question. The results obtained from studies of the stoichiometry of activation are consistent with the idea that the number of sites is reduced by mutation, but do not exclude the possibility that some activation can be mediated through the mutated sites. However, we note that the $\beta 2(\mathrm{M} 286 \mathrm{~W})$ mutation has been reported to abolish the actions of the anesthetic drug etomidate (Stewart et al., 2008), whereas in the homomeric $\beta 3$ receptor containing the Y143W mutation, propofol provides $<0.3 \mathrm{kcal} / \mathrm{mol}$ of stabilization energy (Eaton et al., 2015). The second major caveat is that the energetic contributions from each of the remaining, unidentified binding sites, and hence the number of remaining sites, is unknown. For simplicity, we assumed that the remaining sites are energetically equivalent to the sites defined by the $\beta 2(\mathrm{Y} 143)$ and $\beta 2(\mathrm{M} 286)$ residues that each contribute $\sim 1.1 \mathrm{kcal} / \mathrm{mol}$ of stabilization energy.

Further work may provide unambiguous evidence for the presence of additional sites. The most direct evidence, of course, will be elimination of activation by propofol. The candidate regions to be tested include the homologous residues in the $\alpha(+)-\gamma(-)$ interface. Whereas propofol does not protect against modification of $\gamma 2$ (I242C), a residue at the "-" interface of the $\gamma 2$ subunit and homologous to $\beta 2(\mathrm{M} 227)$ that is photolabeled by meta-azi-propofol (Jayakar et al., 2014) by pCMBS (Nourmahnad et al., 2016), $\gamma 2$ (F158), homologous to $\beta 2(\mathrm{Y} 143)$, is located extracellularly from $\gamma 2(\mathrm{I} 242)$. Another potential region includes the $\mathrm{C}^{\prime}$-terminal half of the M4 membrane-spanning domain, where a tryptophan substitution of $\beta 2$ (Y444) selectively impairs receptor activation by propofol (Richardson et al., 2007). This region is of particular interest because a homologous location in the $\alpha 1$ subunit is an important determinant of $\mathrm{GABA}_{\mathrm{A}}$ receptor modulation by several inhaled anesthetics (Jenkins et al., 2002).

The data on the relationship between changes in energies for an unliganded opening and for stabilization by propofol indicate that the substitution by the bulky and hydrophobic side chain of tryptophan does not simply prevent the interaction of propofol with the receptor. Instead, tryptophan appeared to functionally replace the effects of bound propofol in terms of stabilizing the open state. Indeed, the reduction in the stabilization energy contributed by propofol was matched by a decrease in the energy difference between the unliganded open and closed states. This symmetry is consistent with the idea that tryptophan functionally ablates the ability of propofol to interact with the mutated sites.

We probed the functional properties of the sites by substituting tryptophan residues at those positions. The effects of the Y143W and M286W mutations were indistinguishable in terms of the energetic contribution that bound 
propofol makes to stabilizing the open state. This conclusion was reached based on analysis of the model-independent $(\mathrm{O} / \mathrm{C})_{\max } /(\mathrm{O} / \mathrm{C})_{\text {const }}$ ratios and the stabilization energies calculated from the MWC-dependent parameters $N_{\mathrm{P}}$ and $c_{\mathrm{P}}$. One interpretation is that binding of propofol to the unmutated sites makes an indistinguishable energetic contribution to activation by propofol.

In contrast, analysis of the parameter $K_{\mathrm{P}}$ indicated that the site affected by the M286W mutation has a higher affinity than that affected by Y143W by approximately 2 -fold. It is certainly not surprising that these two classes of site differ, as they are proposed to be composed of distinct sets of amino acid side chains and are likely quite distinct in terms of the exposure to membrane lipids. In fact, it is perhaps more surprising that the energetic contributions are so similar, given that propofol might be expected to produce different perturbations of the receptor structure when bound at the two types of site.

One assumption of the MWC model is that the properties of all sites for a given agonist are identical in terms of both $K$ and $c$. Our data indicate that this assumption is not correct for propofol, although the difference in $K_{\mathrm{P}}$ is only about 2 -fold. In principle, this difference is not critical: since the sites are nonoverlapping, the situation is analogous to the action of two distinct agonists on the receptor, as shown in eq. 6. Accordingly, this observation does not provide any insight into the overall applicability of the model. However, it complicates the analysis because it is not clear how to partition the numbers of assumed sites for $N_{\mathrm{P}}>4$. In practical terms, the value for $K_{\mathrm{P}}$ fit to the activation data is an average of the various values. For the analysis of the relationship between $\mathrm{EC}_{50}$, $\mathrm{P}$ and $\mathrm{L}$ (Fig. 6), the different values for $K_{\mathrm{P}}$ shift the predicted curves for receptors containing mutations to propofol-binding sites up and down but not left and right. This may increase the deviation between predicted and experimental values for $\mathrm{EC}_{50, \mathrm{P}}$.

In summary, our analyses indicate that each of the four known propofol-binding sites makes an equal and independent energetic contribution to receptor activation by propofol. The two classes of sites differ by approximately 2 -fold in terms of affinity of the resting receptor for propofol. We also infer that receptors may contain one or two additional agonist sites for propofol, but this suggestion will have to be tested experimentally. The overall analysis indicates that the MWC cyclic model for receptor activation is able to quantitatively describe the relationship between the $\mathrm{EC}_{50}$ for activation by propofol and changes in basal activity of the receptor due to incorporation of a gain-of-function mutation or application of an agent active at the transmitter-binding site.

\section{Acknowledgments}

The authors thank Albert Wu and Xiaoyi Gao for help with electrophysiological recordings.

\section{Authorship Contributions}

Participated in research design: Forman, Steinbach, Akk.

Conducted experiments: Shin, Germann, Johnson.

Performed data analysis: Shin, Germann, Johnson, Forman, Steinbach, Akk.

Wrote or contributed to the writing of the manuscript: Shin, Germann, Johnson, Forman, Steinbach, Akk.

\section{References}

Adodra S and Hales TG (1995) Potentiation, activation and blockade of $\mathrm{GABA}_{\mathrm{A}}$ receptors of clonal murine hypothalamic GT1-7 neurones by propofol. Br J Pharmacol 115:953-960.
Akk G, Shin DJ, Germann AL, and Steinbach JH (2017) GABA receptor activation in the allosteric coagonist model framework: relationship between $\mathrm{EC}_{50}$ and basal activity. Mol Pharmacol 93:90-100.

Amin J and Weiss DS (1993) GABA receptor needs two homologous domains of the $\beta$-subunit for activation by GABA but not by pentobarbital. Nature 366:565-569.

Baumann SW, Baur R, and Sigel E (2002) Forced subunit assembly in $\alpha 1 \beta 2 \gamma 2$ $\mathrm{GABA}_{\mathrm{A}}$ receptors. Insight into the absolute arrangement. $J$ Biol Chem 277: $46020-46025$.

Bracamontes J, McCollum M, Esch C, Li P, Ann J, Steinbach JH, and Akk G (2011) Occupation of either site for the neurosteroid allopregnanolone potentiates the opening of the $\mathrm{GABA}_{\mathrm{A}}$ receptor induced from either transmitter binding site. $\mathrm{Mol}$ Pharmacol 80:79-86.

Bracamontes JR and Steinbach JH (2009) Steroid interaction with a single potentiating site is sufficient to modulate GABA-A receptor function. Mol Pharmacol 75:973-981.

Chang Y, Wang R, Barot S, and Weiss DS (1996) Stoichiometry of a recombinant $\mathrm{GABA}_{\mathrm{A}}$ receptor. $J$ Neurosci 16:5415-5424.

Chang Y and Weiss DS (1999) Allosteric activation mechanism of the $\alpha 1 \beta 2 \gamma 2$ $\gamma$-aminobutyric acid type A receptor revealed by mutation of the conserved M2 leucine. Biophys J 77:2542-2551.

Eaton MM, Cao LQ, Chen Z, Franks NP, Evers AS, and Akk G (2015) Mutational analysis of the putative high-affinity propofol binding site in human $\beta 3$ homomeric $\mathrm{GABA}_{\mathrm{A}}$ receptors. Mol Pharmacol 88:736-745.

Eaton MM, Germann AL, Arora R, Cao LQ, Gao X, Shin DJ, Wu A, Chiara DC, Cohen JB, Steinbach JH, et al. (2016) Multiple non-equivalent interfaces mediate direct activation of $\mathrm{GABA}_{\triangle}$ receptors by propofol. Curr Neuropharmacol 14:772-780.

Forman SA and Stewart D (2012) Mutations in the $\mathrm{GABA}_{\mathrm{A}}$ receptor that mimic the allosteric ligand etomidate. Methods Mol Biol 796:317-333.

Franks NP (2015) Structural comparisons of ligand-gated ion channels in open, closed, and desensitized states identify a novel propofol-binding site on mammalian $\gamma$-aminobutyric acid type A receptors. Anesthesiology 122:787-794.

Germann AL, Shin DJ, Manion BD, Edge CJ, Smith EH, Franks NP, Evers AS, and Akk G (2016) Activation and modulation of recombinant glycine and GABA receptors by 4-halogenated analogues of propofol. $\mathrm{Br}$ J Pharmacol 173:3110-3120.

Hales TG and Lambert JJ (1991) The actions of propofol on inhibitory amino acid receptors of bovine adrenomedullary chromaffin cells and rodent central neurones. $\mathrm{Br}$ J Pharmacol 104:619-628.

Jayakar SS, Zhou X, Chiara DC, Dostalova Z, Savechenkov PY, Bruzik KS, Dailey WP, Miller KW, Eckenhoff RG, and Cohen JB (2014) Multiple propofol-binding sites in a $\gamma$-aminobutyric acid type A receptor $\left(\mathrm{GABA}_{\mathrm{A}} \mathrm{R}\right)$ identified using a photoreactive propofol analog. J Biol Chem 289:27456-27468.

Jenkins A, Andreasen A, Trudell JR, and Harrison NL (2002) Tryptophan scanning mutagenesis in TM4 of the $\operatorname{GABA}\left({ }_{\mathrm{A}}\right)$ receptor $\alpha 1$ subunit: implications for modulation by inhaled anesthetics and ion channel structure. Neuropharmacology 43:669-678.

Karlin A (1967) On the application of "a plausible model" of allosteric proteins to the receptor for acetylcholine. J Theor Biol 16:306-320.

Krasowski MD, Koltchine VV, Rick CE, Ye Q, Finn SE, and Harrison NL (1998) Propofol and other intravenous anesthetics have sites of action on the $\gamma$-aminobutyric acid type A receptor distinct from that for isoflurane. Mol Pharmacol 53:530-538

Krasowski MD, Nishikawa K, Nikolaeva N, Lin A, and Harrison NL (2001) Methionine 286 in transmembrane domain 3 of the $\mathrm{GABA}_{\mathrm{A}}$ receptor $\beta$ subunit controls a binding cavity for propofol and other alkylphenol general anesthetics. Neuropharmacology 41:952-964.

Monod J, Wyman J, and Changeux JP (1965) On the nature of allosteric transitions: a plausible model. $J$ Mol Biol 12:88-118.

Nourmahnad A, Stern AT, Hotta M, Stewart DS, Ziemba AM, Szabo A, and Forman SA (2016) Tryptophan and cysteine mutations in M1 helices of $\alpha 1 \beta 3 \gamma 2 \mathrm{~L} \gamma$-aminobutyric acid type A receptors indicate distinct intersubunit sites for four intravenous anesthetics and one orphan site. Anesthesiology 125:1144-1158.

Richardson JE, Garcia PS, O'Toole KK, Derry JM, Bell SV, and Jenkins A (2007) A conserved tyrosine in the $\beta 2$ subunit M4 segment is a determinant of $\gamma$-aminobutyric acid type A receptor sensitivity to propofol. Anesthesiology 107:412-418.

Ruesch D, Neumann E, Wulf H, and Forman SA (2012) An allosteric coagonist model for propofol effects on $\alpha 1 \beta 2 \gamma 2 \mathrm{~L} \gamma$-aminobutyric acid type A receptors. Anesthesiology 116:47-55.

Rüsch D and Forman SA (2005) Classic benzodiazepines modulate the open-close equilibrium in $\alpha 1 \beta 2 \gamma 2 \mathrm{~L} \gamma$-aminobutyric acid type A receptors. Anesthesiology 102: 783-792.

Rüsch D, Zhong H, and Forman SA (2004) Gating allosterism at a single class of etomidate sites on $\alpha 1 \beta 2 \gamma 2 \mathrm{~L}$ GABA receptors accounts for both direct activation and agonist modulation. J Biol Chem 279:20982-20992.

Scheller M and Forman SA (2002) Coupled and uncoupled gating and desensitization effects by pore domain mutations in $\left.\mathrm{GABA}_{\mathrm{A}}\right)$ receptors. $J$ Neurosci 22:8411-8421.

Stewart D, Desai R, Cheng Q, Liu A, and Forman SA (2008) Tryptophan mutations at azi-etomidate photo-incorporation sites on $\alpha 1$ or $\beta 2$ subunits enhance $\mathrm{GABA}_{\mathrm{A}}$ receptor gating and reduce etomidate modulation. Mol Pharmacol 74:1687-1695.

Ueno S, Bracamontes J, Zorumski C, Weiss DS, and Steinbach JH (1997) Bicuculline and gabazine are allosteric inhibitors of channel opening of the $\mathrm{GABA}_{\mathrm{A}}$ receptor. $J$ Neurosci 17:625-634.

Yip GM, Chen ZW, Edge CJ, Smith EH, Dickinson R, Hohenester E, Townsend RR, Fuchs K, Sieghart W, Evers AS, et al. (2013) A propofol binding site on mammalian $\mathrm{GABA}_{\mathrm{A}}$ receptors identified by photolabeling. Nat Chem Biol 9:715-720.

Ziemba AM and Forman SA (2016) Correction for inhibition leads to an allosteric co-agonist model for pentobarbital modulation and activation of $\alpha 1 \beta 3 \gamma 2 \mathrm{~L} \mathrm{GABA}_{A}$ Receptors. PLoS One 11:e0154031.

Address correspondence to: Gustav Akk, Department of Anesthesiology, Washington University School of Medicine, Campus Box 8054, 660 S. Euclid Avenue, St. Louis, MO 63110. E-mail: akk@morpheus.wustl.edu 